\title{
More Than Carbazole Derivative Activates Room Temperature Ultralong Organic Phosphorescence of Benzoindole Derivative
}

\author{
Authors: Chen Qian, ${ }^{\dagger,+}$ Zhimin Ma, ${ }^{\dagger,+}$ Xiaohua Fu, ${ }^{\dagger}$ Xue Zhang, ${ }^{\dagger}$ Zewei Li, ${ }^{\dagger}$ Huiwen Jin, ${ }^{\dagger}$ \\ Mingxing Chen, ${ }^{\star}$ Hong Jiang, ${ }^{\dagger}$ Xinru Jia ${ }^{\star}$ and Zhiyong Ma ${ }^{\dagger *}$
}

\begin{abstract}
Affiliations: Technology, Beijing 100029, China 100871, China

${ }^{+}$These authors contributed equally.

*Correspondence to: mazhy@mail.buct.edu.cn.
\end{abstract}

'Beijing Advanced Innovation Center for Soft Matter Science and Engineering, State Key Laboratory of Organic-Inorganic Composites, College of Chemical Engineering, Beijing University of Chemical

\$Beijing National Laboratory for Molecular Sciences, Key Laboratory of Polymer Chemistry and Physics of the Ministry of Education, College of Chemistry and Molecular Engineering, Peking University, Beijing

Abstract: Herein, we report four carbazole/1H-benzo[f]indole $(\mathrm{Cz} / \mathrm{Bd})$ derivatives with increasing $\mathrm{Bd}$ substitution (Bd number $=0 \sim 3$ ), which give a general mechanism for Bd-based ultralong organic phosphorescence. To physically isolate $\mathrm{Cz}$ and $\mathrm{Bd}$, we synthesized $\mathrm{Cz}$ and $\mathrm{Bd}$ in the lab, separately. According to experimental results, we draw several important points. The first important point is that $\mathrm{Bd}$ and its derivatives commonly possess two groups of intrinsic phosphorescence bands, of which short-lifetime band at $\sim 450 \mathrm{~nm}$ is assigned to the molecular phosphorescence of their neutral molecules and of which typical ultralong phosphorescence bands at $560 \mathrm{~nm}, 610 \mathrm{~nm}$ and $660 \mathrm{~nm}$ are assigned to their radical cations. Amazingly, PMMA films (1wt.\%) of $\mathrm{CNCzBdBr}$ and $\mathrm{CN} 2 \mathrm{BdBr}$ both demonstrate photo-activated room-temperature ultralong organic phosphorescence while this doesn't happen to $\mathrm{Bd}$ and $\mathrm{CN} 3 \mathrm{Bd}$. The second important point is that activation of ultralong phosphorescence from $\mathrm{Bd}$ derivatives involves three factors: well dispersion with limited amount in matrix, generation of $\mathrm{Bd}$ derivatives' radical cations and stabilizing radical cations mediated by matrix. $\mathrm{Cz}$ derivative can function as a matrix to activate (room temperature) ultralong organic phosphorescence of $\mathrm{Bd}$ derivative but its activation function can be replaced by other methods such as photo-activation. The third important point is that the photo-activated ultralong organic phosphorescence is closely related to molecular structure of $\mathrm{Bd}$ derivative and stability of its radical cation. The fourth important point is that for double-carbazole system with trace isomer its room temperature ultralong organic phosphorescence originates at least from synergistic effect of monosubstituted product and disubstituted product of $\mathrm{Bd}$. Furthermore, it is discovered that several other matrixes can also activate room-temperature ultralong organic phosphorescence of $\mathrm{Bd}$ derivatives, further verifying the second important point. To our best knowledge, this study is a big breakthrough in ultralong organic phosphorescence and will probably open a new era for its development. 
Graphic Abstract: We successfully acquired four $\mathrm{Cz} / \mathrm{Bd}$ derivatives $(\mathrm{CN} 2 \mathrm{CzBr}, \mathrm{CNCzBdBr}$, $\mathrm{CN} 2 \mathrm{BdBr}$ and $\mathrm{CN} 3 \mathrm{Bd}$ ) by using lab-synthesized $\mathrm{Cz}$ and lab-synthesized $\mathrm{Bd}$. $\mathrm{Bd}$ and its derivatives feature double groups of intrinsic phosphorescence bands, of which the short-wavelength phosphorescence band is assigned to the molecular phosphorescence of $\mathrm{Bd}$ derivative and of which the ultralong phosphorescence at long wavelengths are ascribed to $\mathrm{Bd}$ derivative's radical cations. Fascinatingly, $\mathrm{CNCzBdBr}$ and $\mathrm{CN} 2 \mathrm{BdBr}$ manifest photo-activated ultralong phosphorescence at room temperature in PMMA film but this doesn't happen to Bd and CN3Bd. Activation of room temperature ultralong phosphorescence from $\mathrm{Bd}$ derivatives involves three factors: well dispersion with limited amount in matrix, generation of $\mathrm{Bd}$ derivatives' radical cations and stabilizing radical cations mediated by matrix. Generally, the intrinsic ultralong phosphorescence of Bd derivatives can be activated by $\mathrm{Cz}$ derivatives. However, the activation function of $\mathrm{Cz}$ derivatives can be replaced by other methods such as photo-activation or other matrixes. Importantly, the photo-activated ultralong phosphorescence is closely related to molecular structure of $\mathrm{Bd}$ derivatives and stability of $\mathrm{Bd}$ derivatives' radical cations. Moreover, for some $\mathrm{Cz}$ systems synthesized from commercial $\mathrm{Cz}$, their ultralong phosphorescence might originate from synergistic effect of two or even more Bd derivatives. This work might be a milestone in ultralong organic phosphorescence and open a new era for its development.

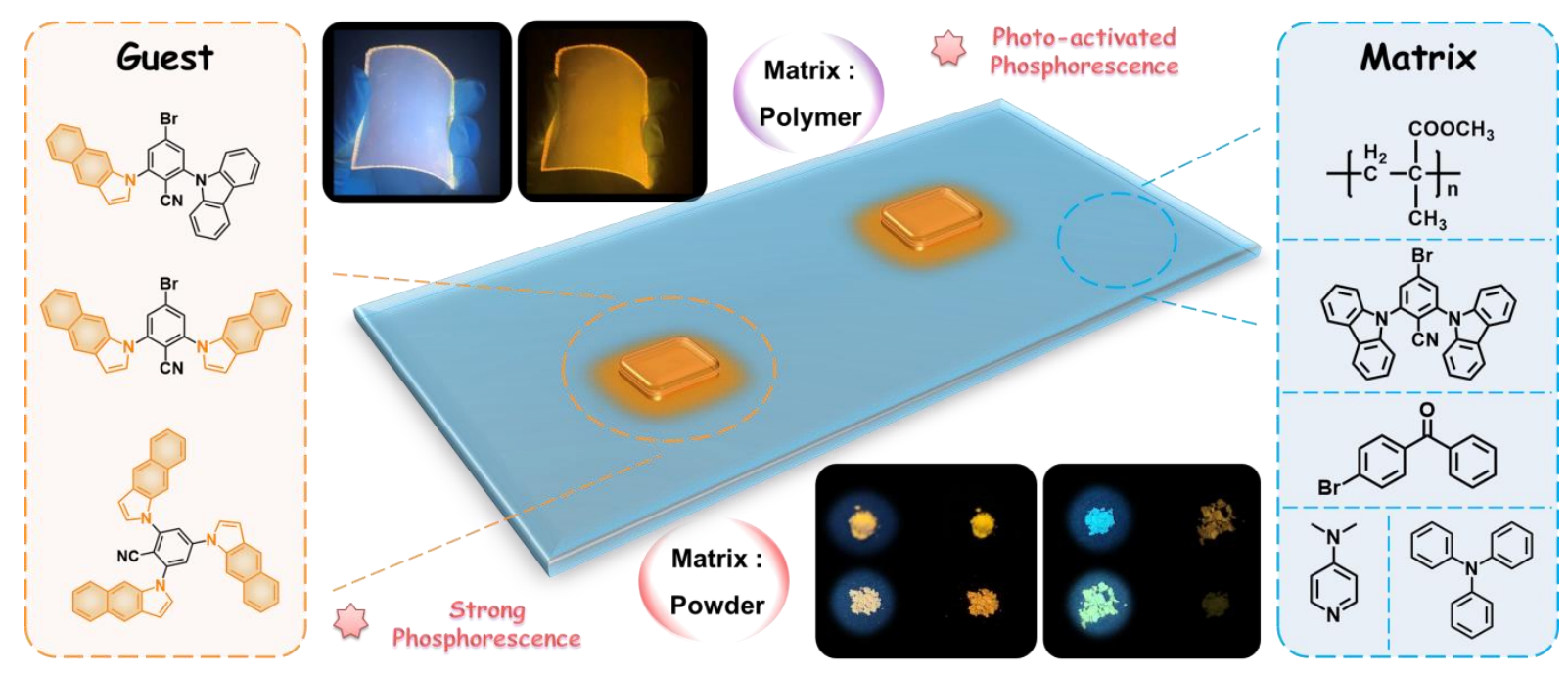


Main Text: Ultralong organic phosphorescence has been attracting considerable attention $^{1-3}$ in past years owing to its superiorities of low cost, low toxicity, flexible structral modification ${ }^{4,5}$ and easy color tunning, ${ }^{6-11}$ and its wide applications in bio-imaging/sensing ${ }^{12-15}$, encryption/anti-counterfeiting ${ }^{16,17}$ and organic light-emitting diode (OLED), ${ }^{18}, 19$ etc. Carbazole $(\mathrm{Cz})$ derivatives are promising light emitters or hole-transporting materials because of carbazole's coplannar configuration, which is conducive to electron comminication or charge carrier mobility. ${ }^{20}$ Since that H-aggregation of carbazole derivatives stabilizes triplet excited states for ultralong organic phosphorescence was reported in $2015,{ }^{2}$ carbazole has become a star molecule in fabricating ultralong organic phosphorescence and hundreds of papers have been published. ${ }^{21-27}$ However, recently Prof. Liu discovered that commercial carbazole contains trace carbazole isomer $(1 \mathrm{H}-$ benzo[f]indole, $\mathrm{Bd})$ and the isomer is convincingly involved in the origination of ultralong organic phosphorescence. ${ }^{3,28}$ They suggested that $\mathrm{Cz}$ and $\mathrm{Bd}$ moieties in close proximity could act as a microplanar heterojunction to generate photoinduced charge-separated states and further to produce intense ultralong organic phosphorescence. According to this research, the previously published results of ultralong organic phosphorescence from carbazole derivatives are actually integrated properties of pure carbazole derivatives and pure Bd's counterparts. ${ }^{2}$, 14, 29-32 Unfortunately, the intrinsic photophysical property of pure Bd's counterpart, which is necessary for clearer elucidation of the mechanism for Cz\&Bd-based ultralong organic phosphorescence, is still unclear because high pure $\mathrm{Bd}$ cannot be obtained by refining commercial $\mathrm{Cz}$ via HPLC and it is inevitable that the refined Bd contains trace carbazole. Thus, what's the 
real truth of Cz\&Bd-based ultralong organic phosphorescence?

To physically isolate $\mathrm{Cz}$ and $\mathrm{Bd}$, we synthesized $\mathrm{Cz}$ and $\mathrm{Bd}$ in the lab, separately. Herein, we report four $\mathrm{Cz} / \mathrm{Bd}$ derivatives (Figure $1 \mathrm{a} \& 1 \mathrm{~b}$ ), $\mathrm{CN} 2 \mathrm{CzBr}$ with two carbazole units, $\mathrm{CNCzBdBr}$ with one carbazole and one benzoindole, $\mathrm{CN} 2 \mathrm{BdBr}$ with two benzoindole groups and $\mathrm{CN} 3 \mathrm{Bd}$ with three benzoindole moieties, which give a general mechanism for Bd-based ultralong organic phosphorescence. According to temperature-variable photoluminescence (PL) spectra, CN2CzBr in PMMA film (1 wt.\%) shows molecular phosphorescence peaked at $439 \mathrm{~nm}$, and the typical three phosphorescence bands over $550 \mathrm{~nm}$ (which were widely reported in previous carbazole system) were not detected; Interestingly, $\mathrm{Bd}, \mathrm{CNCzBdBr}, \mathrm{CN} 2 \mathrm{BdBr}$ and $\mathrm{CN} 3 \mathrm{Bd}$ in PMMA film (1wt.\%) displayed two groups of phosphorescence bands, one of which was located at $\sim 450 \mathrm{~nm}$ and the other of which were located at $\sim 560 \mathrm{~nm}, \sim 610 \mathrm{~nm}, \sim 660 \mathrm{~nm}$. The first important point is that $\mathrm{Bd}$ and its derivatives usually possess two groups of intrinsic phosphorescence bands, of which short-wavelength band is assigned to the molecular phosphorescence of $\mathrm{Bd}$ derivative and of which typical three phosphorescence bands are assigned to $\mathrm{Bd}$ derivative's radical cations. Amazingly, the PMMA films (1wt.\%) of $\mathrm{CNCzBdBr}$ and $\mathrm{CN} 2 \mathrm{BdBr}$ both demonstrated photo-activated room temperature ultralong organic phosphorescence at $560 \mathrm{~nm}, 610 \mathrm{~nm}$ and $660 \mathrm{~nm}$ while this didn't happen to the PMMA films of Bd and CN3Bd. Especially for CN2BdBr, without any $\mathrm{Cz}$, the intense room-temperature ultralong organic phosphorescence still appeared after photo-activation. The second important point is that activation of room temperature ultralong phosphorescence from $\mathrm{Bd}$ derivatives involves three factors: well 
dispersion with limited amount in matrix, generation of $\mathrm{Bd}$ derivatives' radical cations and stabilizing radical cations mediated by matrix. $\mathrm{Cz}$ derivative can function as a matrix to activate (room temperature) ultralong organic phosphorescence of Bd derivative but its activation function can be replaced by other methods. The third important point is that the photo-activated ultralong organic phosphorescence is closely related to molecular structure of Bd derivative and stability of Bd derivative's radical cations, which will open a new landscape for ultralong organic phosphorescence. Then, single component or multiple components of $\mathrm{CNCzBdBr}, \mathrm{CN} 2 \mathrm{BdBr}$ and $\mathrm{CN} 3 \mathrm{Bd}$ was/were doped into $\mathrm{CN} 2 \mathrm{CzBr}$ and the typical three phosphorescence bands appeared and enhanced remarkably. The fourth important point is that for double-carbazole system with trace isomer its room temperature ultralong organic phosphorescence originates at least from synergistic effect of monosubstituted product and disubstituted product of $\mathrm{Bd}$. Furthermore, it is discovered that several other matrixes can also activate room-temperature ultralong organic phosphorescence of Bd derivatives, further verifying the second important point. To our best knowledge, this study is a big breakthrough in ultralong organic phosphorescence and will probably open a new era for its development. 

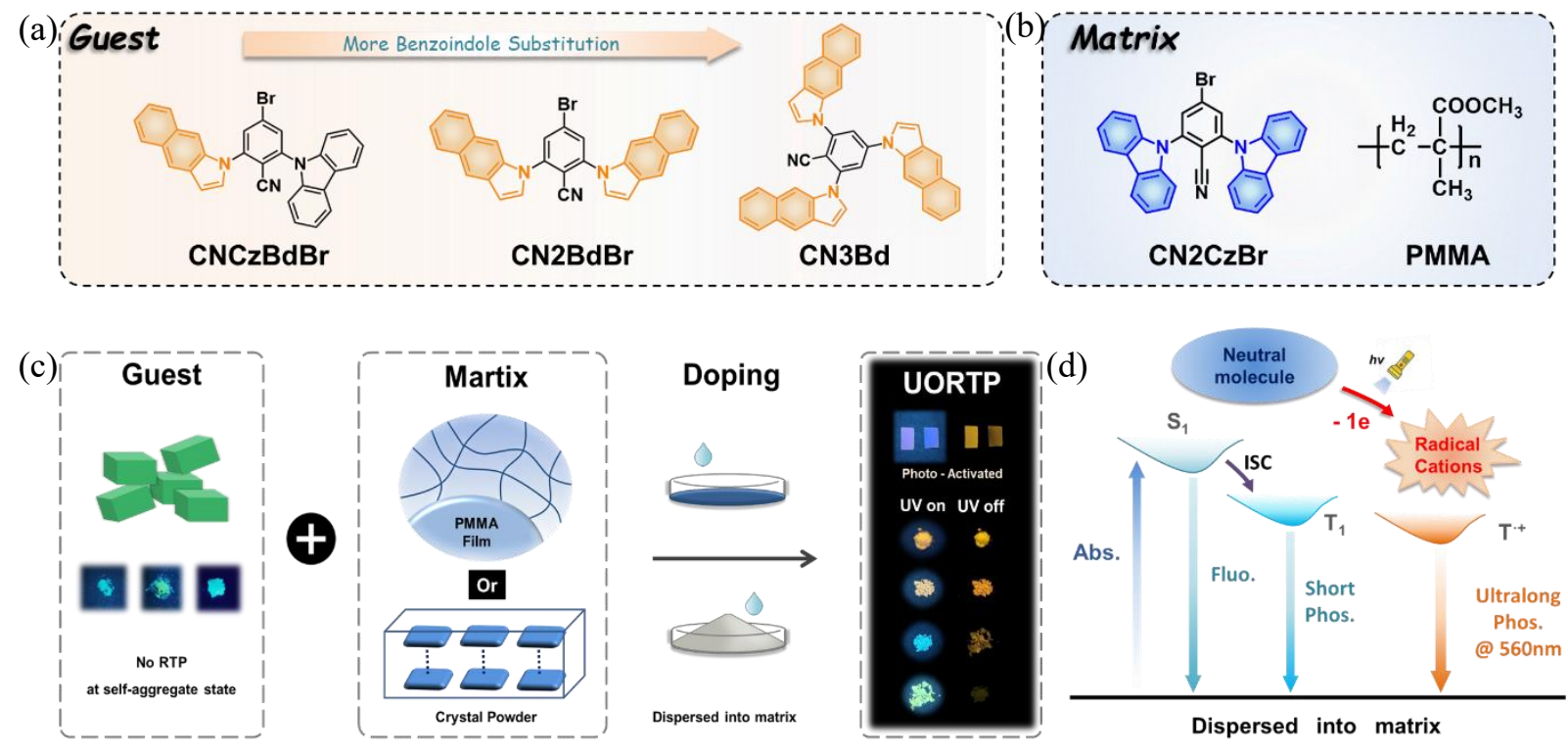

Figure 1. (a) Molecular structures of $\mathrm{Bd}$ derivatives $(\mathrm{CNCzBdBr}, \mathrm{CN} 2 \mathrm{BdBr}$ and $\mathrm{CN} 3 \mathrm{Bd})$ which function as guest; (b) molecular structures of $\mathrm{CN} 2 \mathrm{CzBr}$ and PMMA which function as matrix; (c) (photo-activated) room temperature ultralong phosphorescence is lighted up when guest is doped into matrix; (d) proposed phosphorescence mechanism for $\mathrm{Bd}$ and $\mathrm{Bd}$ derivatives in matrix.

\section{Results and Discussion}

Synthesis and characterization. 1H-benzo[f]indole (Bd) was acquired as light yellow powder via seven-step reactions, starting from 3-amino-2-naphthoic acid (Scheme S1). Carbazole $(\mathrm{Cz})$ was obtained as white powder through two-step reactions with aniline as the starting reagent. I have to stress that all the $\mathrm{Bd}$ and $\mathrm{Cz}$ used in this study are from lab synthesis without further declaration. $\mathrm{CN} 2 \mathrm{CzBr}$ was afforded as white powder by typical substitution reaction between 4-bromo-2,6-difluorobenzonitrile and $\mathrm{Cz}$. $\mathrm{CN} 2 \mathrm{BdBr}$ and $\mathrm{CN} 3 \mathrm{Bd}$ were both obtained as yellow powder via typical substitution reaction between 4-bromo-2,6-difluorobenzonitrile and $\mathrm{Bd}$ by controlling the reaction temperature. 
Asymmetric $\mathrm{CNCzBdBr}$ was acquired as yellow powder by the way of $\mathrm{CNCzBrF}$ and then the substitution reaction between $\mathrm{CNCzBrF}$ and $\mathrm{Bd}$. Also, $\mathrm{CN} 2 \mathrm{CzBr}$ was synthesized with commercial $\mathrm{Cz}$ (named as $\mathrm{CN} 2 \mathrm{CzBr}-\mathrm{com}) .{ }^{1} \mathrm{H} \mathrm{NMR},{ }^{13} \mathrm{C}$ NMR, HR-MS and crystallographic analyses were performed to verify the chemical structures of all the products. The detailed synthetic procedures and molecular characterization are available in the Supporting Information (Scheme S2, Figure S1-S20).

Photophysical properties in solution. Firstly, the photophysical properties of $\mathrm{CN} 2 \mathrm{CzBr}, \mathrm{Bd}$, $\mathrm{CNCzBdBr}, \mathrm{CN} 2 \mathrm{BdBr}$ and $\mathrm{CN} 3 \mathrm{Bd}$ were studied in THF solution $(40 \mu \mathrm{M}$, Figure $\mathrm{S} 21)$. Bd showed an absorbance band at $247 \mathrm{~nm}$ and another group of absorbance bands over $300 \mathrm{~nm}$ (at $330 \mathrm{~nm}, 345 \mathrm{~nm}$ and $361 \mathrm{~nm}$ ), assigned to $\pi \rightarrow \pi n$ transition and $\mathrm{n} \rightarrow \pi \mathrm{t}$ transitions, respectively. $\mathrm{CN} 2 \mathrm{BdBr}$ and $\mathrm{CN} 3 \mathrm{Bd}$ possessed the similar absorbance bands with $\mathrm{Bd}$. The $\pi$ $\rightarrow \pi \mathrm{C}$ transitions of $\mathrm{CN} 2 \mathrm{BdBr}$ and $\mathrm{CN} 3 \mathrm{Bd}$ were peaked at $242 \mathrm{~nm}$ and $243 \mathrm{~nm}$, respectively. The $\mathrm{n} \rightarrow \pi \mathrm{p}$ transitions appeared at $310 \mathrm{~nm}, 356 \mathrm{~nm}$ and $387 \mathrm{~nm}$ for $\mathrm{CN} 2 \mathrm{BdBr}$ and at $310 \mathrm{~nm}$, $359 \mathrm{~nm}$ and $376 \mathrm{~nm}$ for $\mathrm{CN} 3 \mathrm{Bd}$. For $\mathrm{CN} 2 \mathrm{CzBr}$, its $\pi \rightarrow \pi 0$ transition emerged at $229 \mathrm{~nm}$ and its $\mathrm{n} \rightarrow \pi \mathrm{t}$ transitions were located at $287 \mathrm{~nm}, 318 \mathrm{~nm}, 331 \mathrm{~nm}$ and $364 \mathrm{~nm}$. For $\mathrm{CNCzBdBr}$, its $\pi \rightarrow \pi$ transitions appeared at $236 \mathrm{~nm}$ with a shoulder band at $245 \mathrm{~nm}$; and its $\mathrm{n} \rightarrow \pi \mathrm{a}$ transitions were located at $288 \mathrm{~nm}, 309 \mathrm{~nm}, 331 \mathrm{~nm}, 354 \mathrm{~nm}$ and $385 \mathrm{~nm}$, exhibiting the integrated effect of $\mathrm{Bd}$ and $\mathrm{Cz}$. In the photoluminescence spectra (Figure S21b), Bd's emission band was centered $391 \mathrm{~nm}$, assigned to the locally excited (LE) fluorescence. The emission bands of $\mathrm{CN} 2 \mathrm{BdBr}$ and $\mathrm{CN} 3 \mathrm{Bd}$ were peaked at $460 \mathrm{~nm}$ and $482 \mathrm{~nm}$, respectively, ascribed to intramolecular charge transfer (ICT) fluorescence; and their LE fluorescence bands, which should be similar with $\mathrm{Bd}$, didn't appear. For $\mathrm{CN} 2 \mathrm{CzBr}$, its emission band was 
peaked at $414 \mathrm{~nm}$, assigned to the LE fluorescence, because this band is similar with the Cz's LE fluorescence. Moreover, $\mathrm{CNCzBdBr}$ displayed dual emissions at $411 \mathrm{~nm}$ and $496 \mathrm{~nm}$, ascribed to LE fluorescence and ICT fluorescence, respectively.

Photophysical properties in solid state. Then, we investigated the solid-state luminescent properties of $\mathrm{CN} 2 \mathrm{CzBr}, \mathrm{Bd}, \mathrm{CNCzBdBr}, \mathrm{CN} 2 \mathrm{BdBr}$ and $\mathrm{CN} 3 \mathrm{Bd}$ (Figure $\mathrm{S} 22$ ). At room temperature, $\mathrm{CN} 2 \mathrm{CzBr}$ showed two emission bands at $424 \mathrm{~nm}(5.36 \mu \mathrm{s})$ and $462 \mathrm{~nm}(3.04 \mathrm{~ms})$ (Figure S23). In the temperature-variable PL spectra, intensity of the $424 \mathrm{~nm}$ emission band tended to decrease when temperature decreased from $317 \mathrm{~K}$ to $77 \mathrm{~K}$ (Figure S24), verifying its nature of thermally activated delayed fluorescence (TADF); a new emission band at 442 nm appeared and its intensity enhanced rapidly accompanied with the decrease of temperature, which is confirmed to be intrinsic molecular phosphorescence of $\mathrm{CN} 2 \mathrm{CzBr}$ (later discussed in PMMA film section); and intensity of the $462 \mathrm{~nm}$ emission band strengthened sharply along with the cooling process, suggesting its assignment of crystalline phosphorescence. However, $\mathrm{Bd}, \mathrm{CNCzBdBr}, \mathrm{CN} 2 \mathrm{BdBr}$ and $\mathrm{CN} 3 \mathrm{Bd}$ all just showed weak fluorescence at $453 \mathrm{~nm}(4.09 \mathrm{~ns}$, Figure S26), $480 \mathrm{~nm}$ (1.33 ns, Figure S25), $500 \mathrm{~nm}$ (6.39 ns, Figure S28) and $480 \mathrm{~nm}$ (1.85 ns, Figure S30); and no phosphorescence was detected at room temperature (Figure S22). At $77 \mathrm{~K}, \mathrm{CNCzBdBr}$ and $\mathrm{CN} 2 \mathrm{BdBr}$ exhibited ultralong yellow phosphorescence at $560 \mathrm{~nm}, 610 \mathrm{~nm}$ and $660 \mathrm{~nm}$ but the intensity was quite low (Figure S27\&S29); even more, CN3Bd didn't show any ultralong phosphorescence at $77 \mathrm{~K}$ (Figure $\mathrm{S} 31$ ), indicating that it is not beneficial for ultralong phosphorescence when $\mathrm{Bd}$ or its derivatives self-aggregate. 
Temperature-variable photophysical properties in PMMA film.
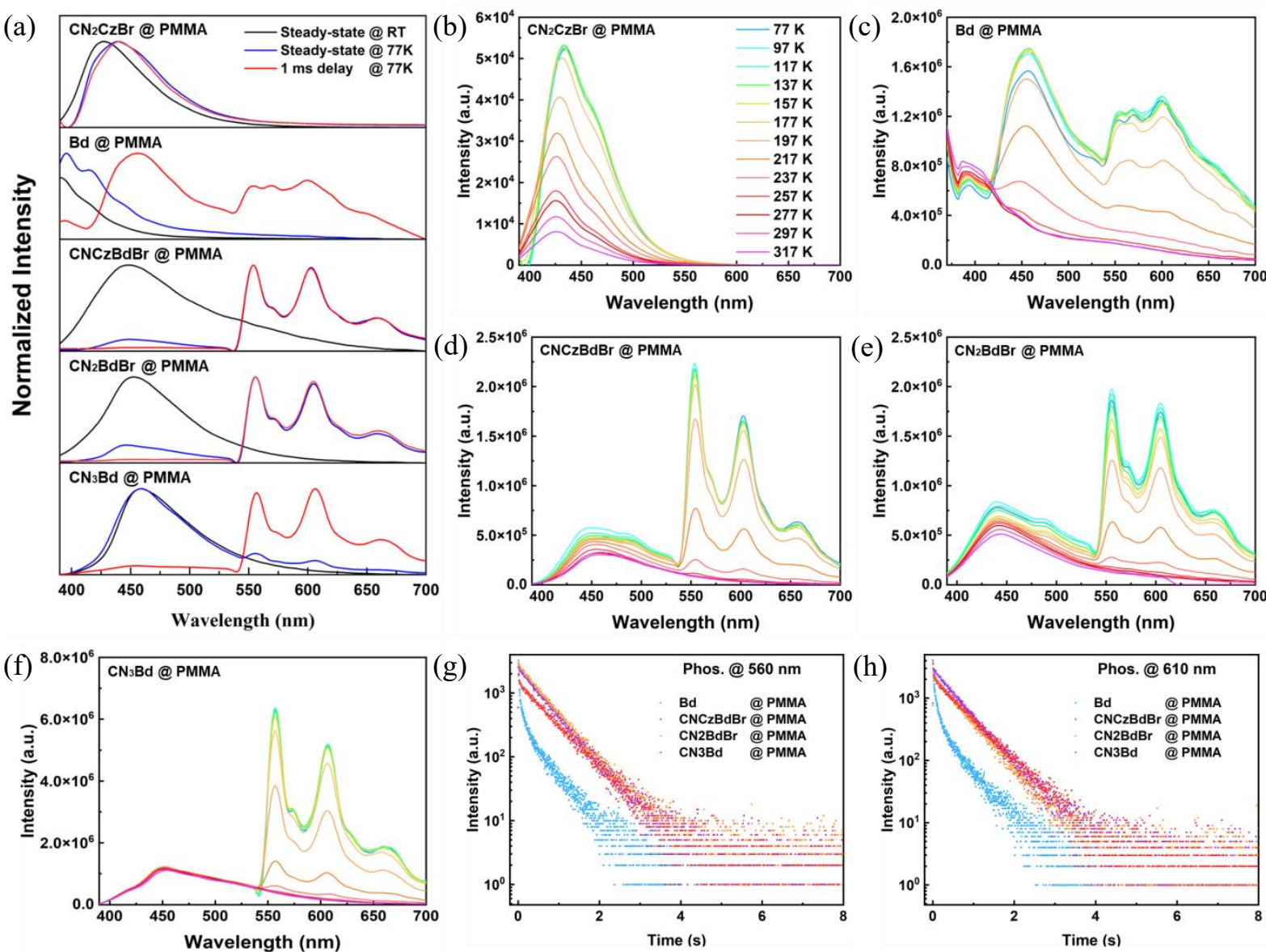

Figure 2. (a) Steady-state and delayed PL spectra at room temperature and at $77 \mathrm{~K}$ of

$\mathrm{CN} 2 \mathrm{CzBr}, \mathrm{Bd}, \mathrm{CNCzBdBr}, \mathrm{CN} 2 \mathrm{BdBr}$ and $\mathrm{CN} 3 \mathrm{Bd}$; temperature-variable PL spectra of (b)

CN2CzBr (steady-state), (c) Bd (delayed), (d) $\mathrm{CNCzBdBr}$ (steady-state), (e) CN2BdBr

(steady-state) and (f) CN3Bd (delayed); (g, h) decayed spectra at $560 \mathrm{~nm}$ and $610 \mathrm{~nm}$ of

$\mathrm{CN} 2 \mathrm{CzBr}, \mathrm{Bd}, \mathrm{CNCzBdBr}, \mathrm{CN} 2 \mathrm{BdBr}$ and $\mathrm{CN} 3 \mathrm{Bd}$ at $77 \mathrm{~K}$. All samples are PMMA films.

To study the intrinsic phosphorescence properties, CN2CzBr, Bd, CNCzBdBr, CN2BdBr and $\mathrm{CN} 3 \mathrm{Bd}$ were doped into PMMA film with the weight ratio of $1 \%$. PMMA film of $\mathrm{CN} 2 \mathrm{CzBr}$ showed an emission band at $427 \mathrm{~nm}$ (Figure 2a) with the lifetime of $14.2 \mu \mathrm{s}$ (Figure S32a) at room temperature, suggesting its nature of thermally activated delayed 
fluorescence (TADF); and phosphorescence was not detected. At $77 \mathrm{~K}$, its emission was centered at $439 \mathrm{~nm}$ (Figure 2a) with the lifetime of $70.9 \mathrm{~ms}$ (Figure S32b), assigned to molecular phosphorescence of $\mathrm{CN} 2 \mathrm{CzBr}$; and the typical three phosphorescence bands over $550 \mathrm{~nm}$ were not observed. In the temperature-variable PL spectra, the emission band red shifted from $427 \mathrm{~nm}$ to $439 \mathrm{~nm}$ and its intensity strengthened gradually along with the decrease of temperature (Figure 2b). Thus, the intrinsic molecular phosphorescence of $\mathrm{CN} 2 \mathrm{CzBr}$ was located at $439 \mathrm{~nm}$ and the ultralong phosphorescence bands over $550 \mathrm{~nm}$ were not ascribed to $\mathrm{CN} 2 \mathrm{CzBr}$.

Surprisingly, $\mathrm{Bd}, \mathrm{CN} 2 \mathrm{BdBr}$ and $\mathrm{CN} 3 \mathrm{Bd}$ all possess two groups of intrinsic phosphorescence bands at $77 \mathrm{~K}$. At room temperature, the film of $\mathrm{Bd}$ showed a week fluorescence band at $391 \mathrm{~nm}$ (Figure 2a) with the lifetime of $8.25 \mathrm{~ns}$ (Figure S33) and no phosphorescence was detected. However, at $77 \mathrm{~K}$, the fluorescence band at $391 \mathrm{~nm}$ still existed and two new groups of phosphorescence bands emerged (Figure 2b). The first group was located at $455 \mathrm{~nm}$ with the lifetime of $10.2 \mathrm{~ms}$ (Figure S33). The second group contained the typical three phosphorescence bands at $551 \mathrm{~nm}, 601 \mathrm{~nm}$ and $654 \mathrm{~nm}$ with the approximate lifetimes of $471.5 \mathrm{~ms}, 433.5 \mathrm{~ms}$ and $396.4 \mathrm{~ms}$ (Figure $2 \mathrm{~g} \&$ Figure S33). We put these three phosphorescence bands together as the group two because they usually emerge together and possess similar lifetimes. In the temperature-variable delayed PL spectra, these two groups of emission bands newly appeared and then enhanced gradually when temperature decreased (Figure 2c), verifying their characteristics of phosphorescence. As for $\mathrm{CN} 2 \mathrm{BdBr}$ and $\mathrm{CN} 3 \mathrm{Bd}$, their PMMA films showed fluorescence bands (Figure 2a) at $455 \mathrm{~nm}$ with the lifetime of 3.88 ns (Figure S35) and $459 \mathrm{~nm}$ with the lifetime of $4.43 \mathrm{~ns}$ (Figure S36) at room temperature, 
respectively; not any phosphorescence band was detected. At $77 \mathrm{~K}, \mathrm{CN} 2 \mathrm{BdBr}$ exhibited two groups of characteristic phosphorescence bands (Figure 2a). The short-wavelength group was centered at $446 \mathrm{~nm}$ with the lifetime of $17.15 \mathrm{~ms}$ (Figure S35); the long-wavelength group were the typical three phosphorescence bands at $554 \mathrm{~nm}(576.6 \mathrm{~ms}), 607 \mathrm{~nm}(570.1 \mathrm{~ms})$ and $663 \mathrm{~nm}(572.1 \mathrm{~ms})$ (Figure 2g\&Figure S35). In the temperature-variable steady-state PL spectra, these two groups of emission bands newly appeared and then strengthened sharply with the decreasing temperature (Figure 2e), confirming their nature of phosphorescence. Also, CN3Bd displayed almost the same temperature-variable phosphorescence property as $\mathrm{CN} 2 \mathrm{BdBr}$ (Figure 2f\&S36). Though $\mathrm{Bd}, \mathrm{CN} 2 \mathrm{BdBr}$ and CN3Bd feature two similar groups of intrinsic phosphorescence bands, the relative intensity of each band was closely related to the molecular structure, especially for the typical three phosphorescence bands. According to Prof. Liu's work, it is rational that the typical three phosphorescence bands originated from Bd derivative's radical cation, which will be further confirmed by electron spin resonance (ESR) spectra; and we speculated that the short-wavelength phosphorescence was assigned to the intrinsic molecular phosphorescence of $\mathrm{Bd}$ derivative. These results tell us that the intrinsic phosphorescence of $\mathrm{Bd}$ derivatives might have nothing to do with $\mathrm{Cz}$. Cooling can activate their intrinsic phosphorescence; $\mathrm{Cz}$ derivatives can also activate $\mathrm{Bd}$ derivatives' intrinsic phosphorescence but are not necessary for the activation.

$\mathrm{CNCzBdBr}$ is special because it is the first organic molecule constructed with both $\mathrm{Cz}$ and Bd. Then, the photophysical property of $\mathrm{CNCzBdBr}$ was also studied in PMMA film. At room temperature, its film showed a fluorescence band at $450 \mathrm{~nm}$ (1.39 ns, Figure 2a\&Figure S34) and weak phosphorescence could be detected because of its unique photo-activation 
(which will be discussed in detail hereinafter). At $77 \mathrm{~K}$, two groups of phosphorescence bands dominated the PL spectra. The first group was located at $452 \mathrm{~nm}$ with the lifetime of $21.39 \mathrm{~ms}$ (Figure S34); the second group were also the typical three phosphorescence bands at $552 \mathrm{~nm}(575.6 \mathrm{~ms}), 604 \mathrm{~nm}(579.1 \mathrm{~ms})$ and $661 \mathrm{~nm}(577.1 \mathrm{~ms})$ (Figure 2g\&Figure S34). The rapid enhancement in the temperature-variable steady-state PL spectra verified that these two groups of luminescence bands were indeed phosphorescence (Figure 2d). Interestingly, the intrinsic phosphorescence property of $\mathrm{CNCzBdBr}$ was almost the same as $\mathrm{Bd}, \mathrm{CN} 2 \mathrm{BdBr}$ and $\mathrm{CN} 3 \mathrm{Bd}$, implying that $\mathrm{Bd}$ dominated the phosphorescence-emitting process.

Photo-activated room-temperature ultralong organic phosphorescence. Marvellously, the PMMA films (1wt.\%) of $\mathrm{CNCzBdBr}$ and $\mathrm{CN} 2 \mathrm{BdBr}$ both manifested photo-activated room-temperature ultralong organic phosphorescence while this didn't happen to PMMA films of $\mathrm{Bd}$ and $\mathrm{CN} 3 \mathrm{Bd}$. The whole photo-activated processes of $\mathrm{CNCzBdBr}$ and $\mathrm{CN} 2 \mathrm{BdBr}$ were present in Figure 3a. The as-prepared PMMA films were blue emitting and no afterglow was observed if portable UV light $(365 \mathrm{~nm}, 16 \mathrm{~W})$ was removed soon. When the portable UV light was kept on, the yellow ultralong phosphorescence of $\mathrm{CNCzBdBr}$ and $\mathrm{CN} 2 \mathrm{BdBr}$ started to be lighted up at $9 \mathrm{~s}$ and $16 \mathrm{~s}$; and their luminescence color both turned to yellowish. The phosphorescence-enhancing process of $\mathrm{CNCzBdBr}$ and $\mathrm{CN} 2 \mathrm{BdBr}$ last $16 \mathrm{~s}$ and $20 \mathrm{~s}$, respectively. At $77 \mathrm{~s}$, when the UV light was switched off, both films displayed intense yellow afterglow. Then, we performed PL spectra to monitor the photo-activated process (Figure 3b\&3c). The newly emerging phosphorescence bands after photo-activation were located at $\sim 560 \mathrm{~nm}, \sim 610 \mathrm{~nm}$ and $\sim 660 \mathrm{~nm}$, ascribed to the intrinsic ultralong phosphorescence bands of their radical cations. When the scanning number increased, the 
intensity of these phosphorescence bands enhanced remarkably, suggesting that the light source of fluorescence spectrophotometer could also activate these phosphorescence bands effectively. Furthermore, kinetic scanning of the photo-activated process was conducted. The photo-activation involved three stages $(1,2,3$ in Figure $3 d)$. The stage 1 didn't witness the emergence of ultralong phosphorescence, which last $48 \mathrm{~s}$ for $\mathrm{CNCzBdBr}$ and $53 \mathrm{~s}$ for CN2BdBr. At stage 2, yellow ultralong phosphorescence newly appeared and its intensity enhanced gradually, which took $152 \mathrm{~s}$ for $\mathrm{CNCzBdBr}$ and $147 \mathrm{~s}$ for $\mathrm{CN} 2 \mathrm{BdBr}$. At stage 3 (from $200 \mathrm{~s}$ to $300 \mathrm{~s}$ ), the intensity of ultralong phosphorescence kept unchanged. Compared with the initial state (with fluorescence only), the intensity of ultralong phosphorescence increased to $152.1 \%$ and $328.5 \%$ for $\mathrm{CN} 2 \mathrm{BdBr}$ and $\mathrm{CNCzBdBr}$ (Figure 3e), respectively. The lifetimes of the photo-activated ultralong phosphorescence were tested to be $232.76 \mathrm{~ms}$ and $111.52 \mathrm{~ms}$ for $\mathrm{CNCzBdBr}$ and $\mathrm{CN} 2 \mathrm{BdBr}$ (Figure 3f), respectively.

To illuminate the mechanism of photo-activated ultralong phosphorescence, electron spin resonance (ESR) spectra were performed. Before UV irradiation, no ESR signal was detected for both films of $\mathrm{CNCzBdBr}$ and $\mathrm{CN} 2 \mathrm{BdBr}$. After UV irradiation for 1 minute, obvious ESR signals appeared, which ranged from $3465 \mathrm{G}$ to $3541 \mathrm{G}$ for $\mathrm{CNCzBdBr}$ and from $3462 \mathrm{G}$ to $3542 \mathrm{G}$ for $\mathrm{CN} 2 \mathrm{BdBr}$ (Figure $3 \mathrm{~g} \& 3 \mathrm{~h}$ ), respectively. More interestingly, the ESR signals enhanced remarkably when UV irradiation last for 3 minutes ( 5 minutes for $\mathrm{CN} 2 \mathrm{BdBr}$ ). The $g$ values of $\mathrm{CNCzBdBr}$ and $\mathrm{CN} 2 \mathrm{BdBr}$ were calculated to be 2.0065 and 2.0064 , which were very close to a free electron (2.0023), verifying that radical cations of $\mathrm{CNCzBdBr}$ and $\mathrm{CN} 2 \mathrm{BdBr}$ were generated by photo-irradiation. Now, we could explain the process of photo-activation clearly. At stage 1, triplet oxygen in the film was cleared by photo. At stage 
2, the radical cations of Bd derivatives began to generate and accumulate by photo irradiation. At stage 3, the quantity of radical cations became saturated because of their limited stability.

(a)

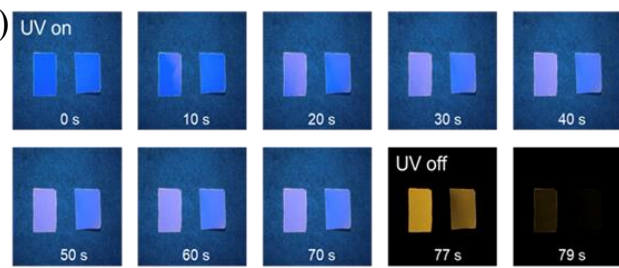

(d)
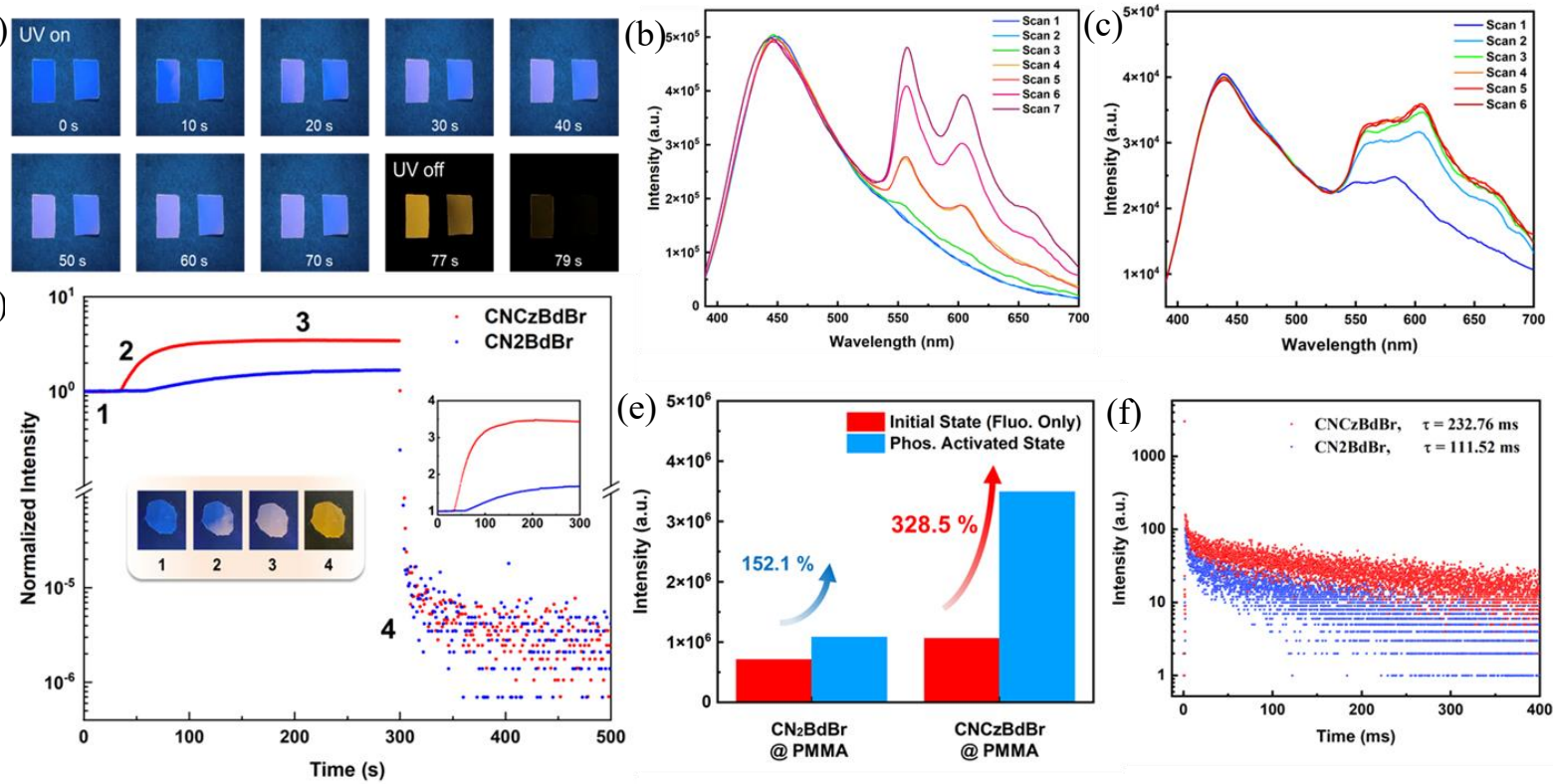

(g)

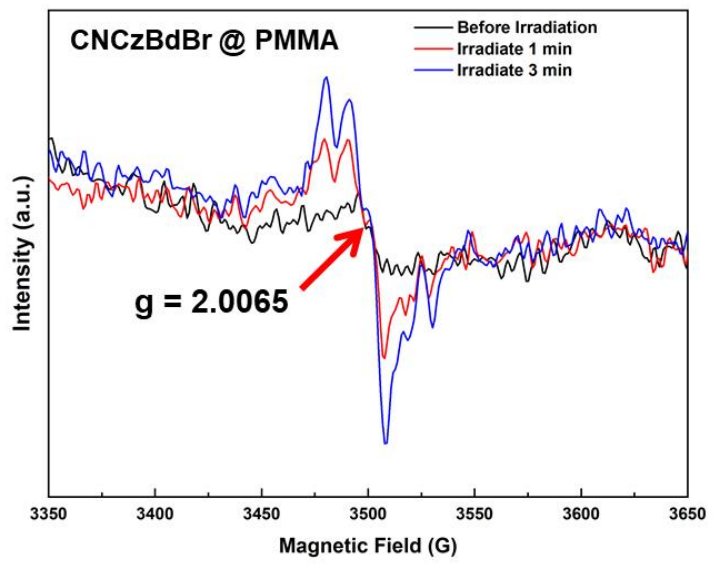

(h)

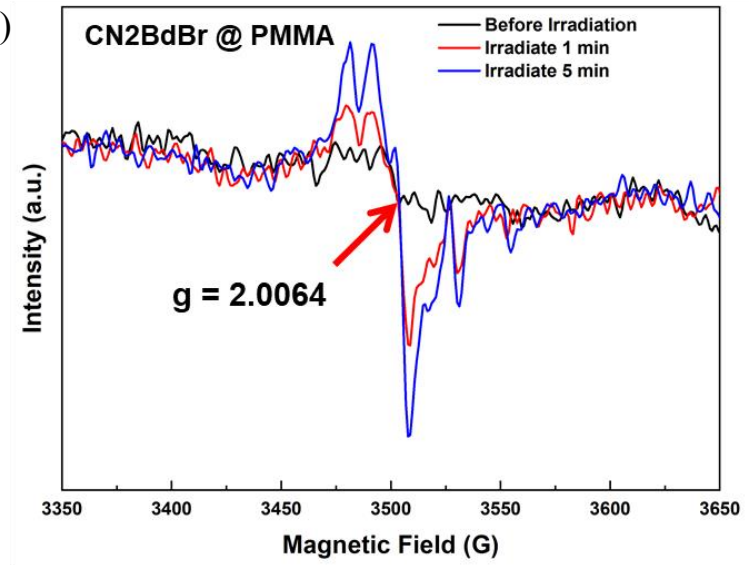

Figure 3. (a) Luminescent images of PMMA films of $\mathrm{CNCzBdBr}$ (left) and $\mathrm{CN} 2 \mathrm{BdBr}$ (right) taken at different time point for the whole photo-activated process; photo-activated phosphorescence enhancement of $\mathrm{CNCzBdBr}$ (b) and $\mathrm{CN} 2 \mathrm{BdBr}$ (c) in PMMA film monitored by steady-state PL spectra; (d) kinetic scannings of $\mathrm{CNCzBdBr}$ and $\mathrm{CN} 2 \mathrm{BdBr}$ films; (e) intensity increase at $560 \mathrm{~nm}$ of $\mathrm{CNCzBdBr}$ and $\mathrm{CN} 2 \mathrm{BdBr}$ films during kinetic scanning; (f) decay spectra at $560 \mathrm{~nm}$ of $\mathrm{CNCzBdBr}$ and $\mathrm{CN} 2 \mathrm{BdBr}$ films after kinetic 
scanning; ESR spectra of (g) $\mathrm{CNCzBdBr}$ and (h) $\mathrm{CN} 2 \mathrm{BdBr}$ films before irradiation and after irradiation.

Moreover, the energy difference $\left(\Delta \mathrm{E}=\mathrm{E}_{\mathrm{M}}{ }^{+}-\mathrm{E}_{\mathrm{M}}\right)$ between the neutral molecules $(\mathrm{M})$ and corresponding radical cations $\left(\mathrm{M}^{+}\right)$was calculated by using density function theory (DFT). Calculated $\Delta \mathrm{E}$ of $\mathrm{Bd}, \mathrm{CNCzBdBr}, \mathrm{CN} 2 \mathrm{BdBr}$ and $\mathrm{CN} 3 \mathrm{Bd}$ were $573.16 \mathrm{~kJ} / \mathrm{mol}, 448.02 \mathrm{~kJ} / \mathrm{mol}$, $430.84 \mathrm{~kJ} / \mathrm{mol}$ and $419.86 \mathrm{~kJ} / \mathrm{mol}$ (Figure 6c, Table S12), suggesting that the stability of $\mathrm{CNCzBdBr}^{+}, \mathrm{CN} 2 \mathrm{BdBr}^{++}$and $\mathrm{CN} 3 \mathrm{Bd}^{++}$are relatively higher and it is easier for $\mathrm{CNCzBdBr}$, $\mathrm{CN} 2 \mathrm{BdBr}$ and $\mathrm{CN} 3 \mathrm{Bd}$ to generate corresponding radical cations under photo irradiation. Besides high stability of radical cations, $\mathrm{CN} 2 \mathrm{BdBr}$ and $\mathrm{CN} 3 \mathrm{Bd}$ showed much higher intersystem crossing (ISC) efficiency than $\mathrm{CN} 3 \mathrm{Bd}$ due to the heavy-atom effect. Therefore, $\mathrm{CN} 2 \mathrm{BdBr}$ and $\mathrm{CN} 3 \mathrm{Bd}$ exhibited remarkable photo-activated room temperature ultralong phosphorescence in PMMA film while Bd and CN3Bd didn’t.

As commonly reported in previous carbazole systems with trace isomer, ${ }^{33-36}$ the typical three ultralong phosphorescence bands at $560 \mathrm{~nm}, 610 \mathrm{~nm}$ and $660 \mathrm{~nm}$ usually emerged at room temperature, verifying that $\mathrm{Cz}$ derivatives can effectively activate intrinsic ultralong phosphorescence bands of Bd deritivatives' radical cations at room temperature. However, our results declare that intrinsic ultralong phosphorescence bands of $\mathrm{Bd}$ deritivatives' radical cations can also be activated by photo at room temperature and the activation function of $\mathrm{Cz}$ derivative can be totally replaced by other methods. Certainly, the photo-activated ultralong phosphorescence is closely related to molecular structures of Bd derivatives so more attention might be paied to discover new Bd derivatives to tune activation rate, PLQY and lifetime of 
the ultralong phosphorescence.

Doping Bd derivatives into $\mathbf{C N 2 C z B r}$. As discussed above, $\mathrm{CN} 2 \mathrm{CzBr}, \mathrm{CNCzBdBr}$, $\mathrm{CN} 2 \mathrm{BdBr}$ and $\mathrm{CN} 3 \mathrm{Bd}$ all didn't show ultralong phosphorescence at room temperature. When doped into $\mathrm{CN} 2 \mathrm{CzBr}$, the intrinsic ultralong phosphorescence of all the three $\mathrm{Bd}$ derivatives were activated at room temperature (Figure S37 S39, Table S1 S3). After screening, the optimized doping ratio of $\mathrm{CNCzBdBr} @ \mathrm{CN} 2 \mathrm{CzBr}, \mathrm{CN} 2 \mathrm{BdBr} @ \mathrm{CN} 2 \mathrm{CzBr}$ and CN3Bd@CN2CzBr were 5\%,10\% and 1\% (Figure 4a\&4b\&4c) with maximal PLQY of $25.1 \%, 10.5 \%$ and $18.0 \%$ (Figure $4 \mathrm{~g}$ ), and corresponding lifetimes of $146.11 \mathrm{~ms}, 85.23 \mathrm{~ms}$ and $95.44 \mathrm{~ms}$ (of the $560 \mathrm{~nm}$ band, Figure $4 \mathrm{e} \& 4 \mathrm{f}$ ), respectively. Comparing the three double-component systems, $\mathrm{CN} 2 \mathrm{CzBr}$ could activate the intrinsic ultralong phosphorescence of $\mathrm{CNCzBdBr}$ more efficiently than $\mathrm{CN} 2 \mathrm{BdBr}$ and $\mathrm{CN} 3 \mathrm{Bd}$. Furthermore, temperature-variable PL spectra were performed to gain deep insight into the CNCzBdBr@CN2CzBr system (5 wt.\%). The typical three phosphorescence bands at 552 nm, $604 \mathrm{~nm}$ and $661 \mathrm{~nm}$ strengthened remarkably when temperature decreased from $317 \mathrm{~K}$ to 77 K (Figure 4d), verifying their nature of ultralong phosphorescence. During the cooling process, three emission bands at $427 \mathrm{~nm}, 451 \mathrm{~nm}$ and $468 \mathrm{~nm}$ split out, assigned to fluorescence/TADF of $\mathrm{CN} 2 \mathrm{CzBr}$, intrinsic phosphorescence of $\mathrm{CNCzBdBr}$ and crystalline phosphorescence of $\mathrm{CN} 2 \mathrm{CzBr}$, respectively. Thus, the luminescence property of $\mathrm{CNCzBdBr} @ \mathrm{CN} 2 \mathrm{CzBr}$ was integration of the luminescence properties of $\mathrm{CNCzBdBr}$ and $\mathrm{CN} 2 \mathrm{CzBr}$.

Likewise, ESR spectra were carried out to evidence existence of radical cations in the 
doped systems (Figure S43) ${ }^{37,38}$ For pure CN2CzBr powder, whether before UV irradiation or after UV irradiation, no ESR signal was detected, implying that no radicals were generated in pure $\mathrm{CN} 2 \mathrm{CzBr}$ powder. For the doped systems $\mathrm{CNCzBdBr} @ \mathrm{CN} 2 \mathrm{CzBr}$, CN2BdBr@CN2CzBr and CN3Bd@CN2CzBr, ESR signal was observed even before UV irradiation, verifying that radical cations of Bd derivatives can exist stably in the matrix of $\mathrm{CN} 2 \mathrm{CzBr}$ without photo-activation. Therefore, the ultralong phosphorescence of doped systems easily appeared without time-consuming photo-activation. After 5 min UV irradiation, the intensity of ESR signal increased a little, further suggesting that UV light can facilitate generation of radical cations.
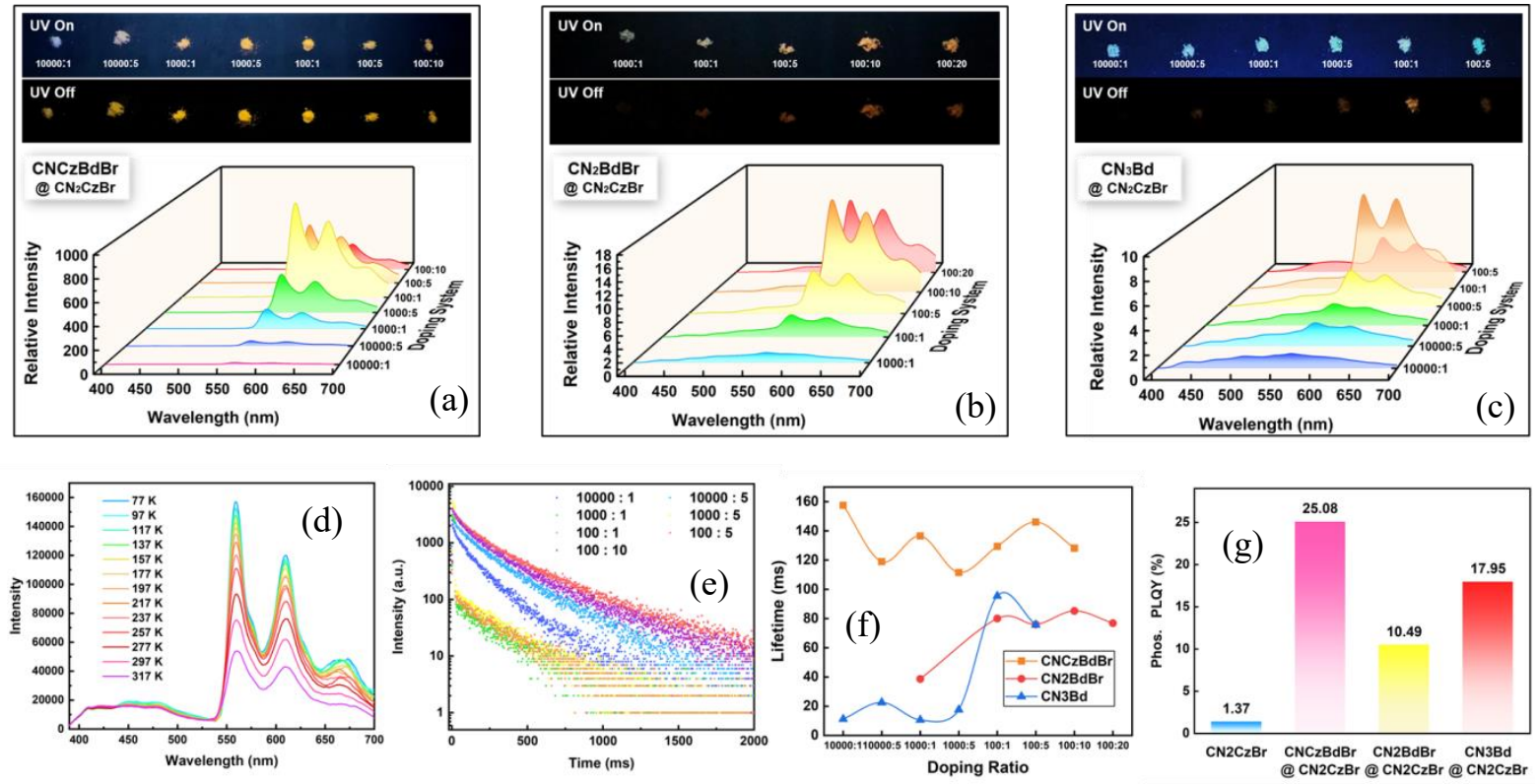

Figure 4. Luminescent and phosphorescent images, steady-state PL spectra at different dopant ratio for the doped system (a) CNCzBdBr@CN2CzBr, (b) CN2BdBr@CN2CzBr and

(c) CN3Bd@CN2CzBr;

(d) Temperature-variable steady-state spectra of

CNCzBdBr@CN2CzBr (5wt.\%); (e) decay spectra of CNCzBdBr@CN2CzBr with different 
ratio; (f) lifetimes at $560 \mathrm{~nm}$ changed along with the dopant ratio for $\mathrm{CNCzBdBr} @ \mathrm{CN} 2 \mathrm{CzBr}$, CN2BdBr@CN2CzBr and CN3Bd@CN2CzBr; $\quad$ (g) Maximal PLQY of CNCzBdBr@CN2CzBr (5wt.\%), CN2BdBr@CN2CzBr (10wt.\%) and CN3Bd@CN2CzBr $(1 \mathrm{wt} . \%)$

Our experimental results agreed well with Prof. Liu's work. ${ }^{3,28}$ Differently, the typical ultralong phosphorescence bands at $552 \mathrm{~nm}, 604 \mathrm{~nm}$ and $661 \mathrm{~nm}$ are the intrinsic phosphorescence of $\mathrm{Bd}$ derivatives' radical cations and $\mathrm{CN} 2 \mathrm{CzBr}$ can activate their intrinsic ultralong phosphorescence probably by heterojunction. Formation of heterojunction requires close proximity between matrix and dopant, which is helpful in generating and stabilizing $\mathrm{Bd}$ derivatives' radical cations due to easy electron communication. With increasing $\mathrm{Bd}$ substitution, molecular geometry of Bd derivatives became more twisted. Higher structure similarity with $\mathrm{CN} 2 \mathrm{CzBr}$ enabled $\mathrm{CNCzBdBr}$ and $\mathrm{CN} 2 \mathrm{CzBr}$ to form effective heterojunction. Thus, the ultralong phosphorescence of $\mathrm{CNCzBdBr}$ can be activated more efficiently by CN2CzBr. Given higher ISC efficiency of CNCzBdBr, CNCzBdBr@CN2CzBr showed higher PLQY than CN2BdBr@CN2CzBr and CN3Bd@CN2CzBr. Moreover, for double-carbazole system (synthesized from commercial $\mathrm{Cz}$ ), its room temperature ultralong organic phosphorescence originates at least from synergistic effect of monosubstituted product and disubstituted product of Bd (Figure S42).

Also, kinetic scannings of $\mathrm{CNCzBdBr} @ \mathrm{CN} 2 \mathrm{CzBr}$ and $\mathrm{CN} 2 \mathrm{BdBr} @ \mathrm{CN} 2 \mathrm{CzBr}$ were conducted (Figure S40). However, after 300 s photo-irradiation, the intensity of ultralong phosphorescence (at $\sim 560 \mathrm{~nm}$ ) kept almost unchanged, implying that the intrinsic ultralong 
phosphorescence of $\mathrm{CNCzBdBr}$ and $\mathrm{CN} 2 \mathrm{CzBr}$ had been fully activated by $\mathrm{CN} 2 \mathrm{CzBr}$.

Other matrixes to activate room temperature ultralong phosphorescence. To replace the activation function of $\mathrm{CN} 2 \mathrm{CzBr}$, several other matrixes were studied. After screening, we found 4-bromobenzophenone (BBP), 4-(dimethylamino)pyridine (DMAP) and triphenylamine (TPA) could also activate the ultralong phosphorescence of $\mathrm{CNCzBdBr}$ at room temperature (Figure 5a). Pure BBP just showed weak blue fluorescence peaked at 450 $\mathrm{nm}$ and no afterglow was observed by naked eyes (Figure 5b\&5c). When 1 wt.\% of CNCzBdBr was doped into BBP, the doped system $\mathrm{CNCzBdBr} @ \mathrm{BBP}$ exhibited strong yellow ultralong phosphorescence at $560 \mathrm{~nm}, 610 \mathrm{~nm}$ and $660 \mathrm{~nm}$ with lifetimes of 101.18 $\mathrm{ms}, 92.55 \mathrm{~ms}$ and $88.12 \mathrm{~ms}$ (Figure 5d\&5e\&5f), implying that triplet excitons of CNCzBdBr's radical cations could also be stabilized by BBP. Pure DMAP displayed weak blue fluorescence centered at $450 \mathrm{~nm}$ and no ultralong phosphorescence band was detected (Figure 5b\&5c). However, the doped system CNCzBdBr@DMAP witnessed the growth of yellow ultralong phosphorescence at $560 \mathrm{~nm}, 610 \mathrm{~nm}$ and $660 \mathrm{~nm}$ with lifetimes of 189.39 ms, $198.63 \mathrm{~ms}$ and $134.18 \mathrm{~ms}$ (Figure 5d\&5e \&5f). Interestingly, pure TPA showed weak blue fluorescence and green afterglow at $526 \mathrm{~nm}$ with lifetime of $87.99 \mathrm{~ms}$ (Figure $5 \mathrm{~b} \& 5 \mathrm{c} \& 5 \mathrm{~d}$ ). Dramatically, there co-existed afterglow of TPA and ultralong phosphorescence bands of CNCzBdBr in the doped system $\mathrm{CNCzBdBr} @$ TPA, where the lifetime at $526 \mathrm{~nm}$ from TPA was $82.01 \mathrm{~ms}$ and the lifetimes at $560 \mathrm{~nm}, 610 \mathrm{~nm}$ and $660 \mathrm{~nm}$ from $\mathrm{CNCzBdBr}$ were 151.27 $\mathrm{ms}, 132.94 \mathrm{~ms}$ and $159.34 \mathrm{~ms}$ (Figure $5 \mathrm{~d} \& 5 \mathrm{e} \& 5 \mathrm{f}$ ). These results further confirm that $\mathrm{Cz}$ derivative function as a matrix to activate room temperature ultralong organic phosphorescence of $\mathrm{Bd}$ derivative and its activation function can be replaced by other 
methods such as other matrixes.

(a) Matrix<smiles>CCCCCCCCCCCCCCC(=O)c1ccccc1</smiles>

BBP<smiles>CN(C)c1ccncc1</smiles>

DMAP<smiles>c1ccc(N(c2ccccc2)c2ccccc2)cc1</smiles>

TPA

$\Delta \mathrm{E}_{\mathrm{BBP}}=74.48 \mathrm{~kJ} / \mathrm{mol}$

$\Delta \mathrm{E}_{\mathrm{DMAP}}=74.47 \mathrm{~kJ} / \mathrm{mol}$

$\Delta \mathrm{E}_{\mathrm{TPA}}=32.88 \mathrm{~kJ} / \mathrm{mol}$

(b)
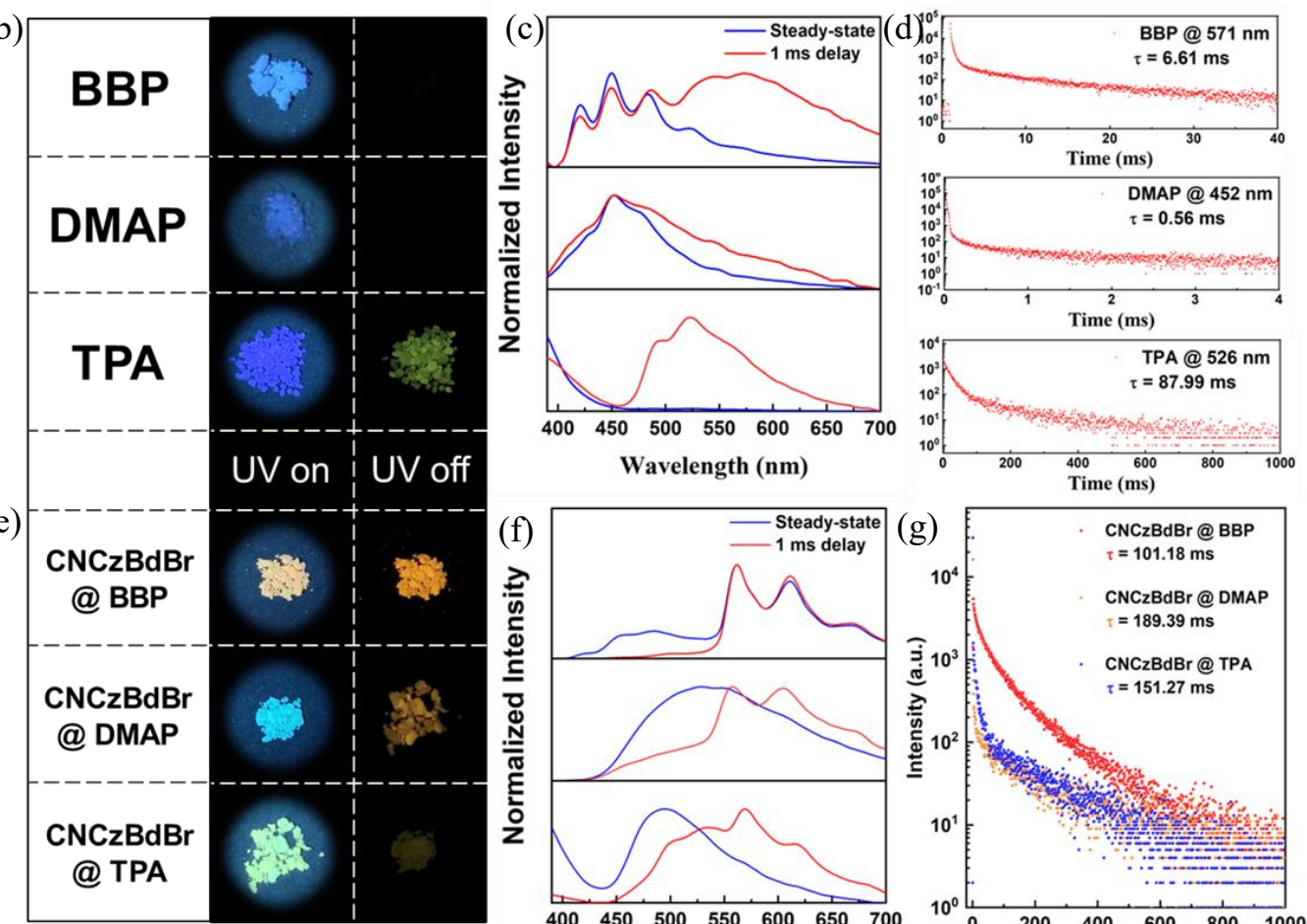

(e)
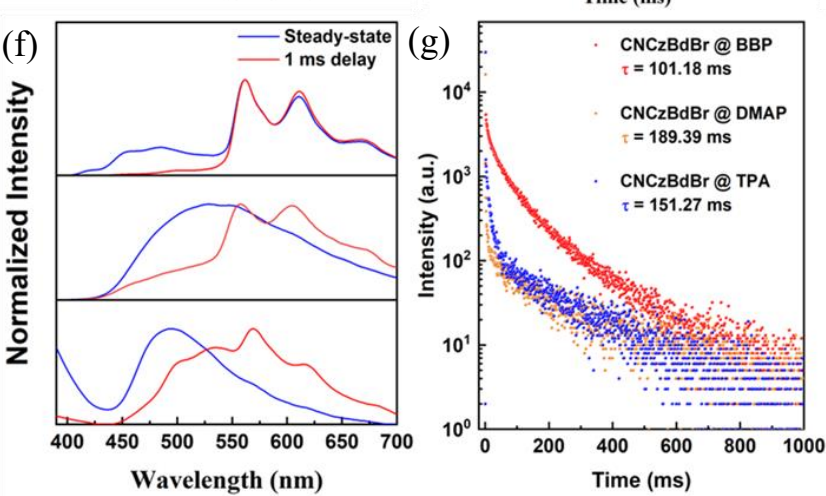

Figure 5. (a) Molecular structures of three matrixes BBP, DMAP and TPA; (b) luminescent and phosphorescent images, (c) steady-state and delayed PL spectra, (d) decay spectra of pure BBP, DMAP and TPA powder; (e) luminescent and phosphorescent images, (f) steady-state and delayed PL spectra, (g) decay spectra of doped system CNCzBdBr@BBP, CNCzBdBr@DMAP and CNCzBdBr@TPA.

Moreover, it was discovered that different matrix greatly affected intensity and lifetime of 
the intrinsic ultralong phosphorescence bands of $\mathrm{Bd}$ derivatives. Probably, the electron-accepting ability of matrix is significant in generating and stabilizing $\mathrm{Bd}$ derivatives's radical cations. The energy difference $\left(\Delta \mathrm{E}=\mathrm{E}_{\mathrm{M}}{ }^{-}-\mathrm{E}_{\mathrm{M}}\right)$ between the netural molecules $(\mathrm{M})$ and corresponding radical ions $\left(\mathrm{M}^{\cdot}\right)$ of matrix was calculated by using DFT. Calculated $\triangle \mathrm{E}$ of CN2CzBr, BBP, DMAP and TPA were $119.82 \mathrm{~kJ} / \mathrm{mol}, 74.48 \mathrm{~kJ} / \mathrm{mol}, 74.47$ $\mathrm{kJ} / \mathrm{mol}$ and $32.88 \mathrm{~kJ} / \mathrm{mol}$ (Table S13), suggesting that CN2CzBr*- BBP•-, DMAP*- and TPA*all exhibited good stability. However, other factors, for example, electron communication efficiency between matrix and guest, triplet oxygen in the matrix, may greatly influence final intensity of ultralong phosphorescence. Thus, all these matrixes can activate room temperature ultralong phosphorescence of $\mathrm{CNCzBdBr}$ but intensity of ultralong phosphoresnce is quite different. Therefore, exploring new matrixes to optimize the ultralong phosphorescence property of $\mathrm{Bd}$ derivatives and exploiting activation mechanism of different matrix will be an interesting topic.

\section{TD-DFT calculations and proposed mechanism of ultralong phosphorescence.}

Furthermore, we employed time-dependent density function theory (TD-DFT) calculation to elucidate the intrinsic phosphorescence of $\mathrm{Bd}$ derivatives and the intrinsic ultralong phosphorescence of $\mathrm{Bd}$ derivatives' radical cations. On one hand, the $\mathrm{S}_{1}$ of $\mathrm{CN} 2 \mathrm{CzBr}$ in monomer state was calculated to be $2.998 \mathrm{eV}(414 \mathrm{~nm})$, in accordance with the experimental value $(427 \mathrm{~nm})$; the calculated $\mathrm{T}_{1}$ and $\mathrm{T}_{1} *$ of $\mathrm{CN} 2 \mathrm{CzBr}$ in monomer state and crystalline state were $2.898 \mathrm{eV}$ ( $428 \mathrm{~nm}$ ) and $2.895 \mathrm{eV}$ ( $428 \mathrm{~nm}$ ) (Figure 6a, Table S5, Figure S45\&46), very close to our experimental results of $439 \mathrm{~nm}$ (molecular phosphorescence) and $462 \mathrm{~nm}$ (crystalline phosphorescence). No triplet energy level was found below $2.26 \mathrm{eV}(550 \mathrm{~nm})$, 
suggesting that the ultralong phosphorescence bands over $550 \mathrm{~nm}$ are not from $\mathrm{CN} 2 \mathrm{CzBr}$. On the other hand, the $S_{n}$ and $T_{n}$ distributions of $B d$ derivatives were also calculated (Table S6-S11, Figure $\mathrm{S} 47-\mathrm{S} 50)$. $\mathrm{S}_{1}$ of $\mathrm{CNCzBdBr}, \mathrm{CN} 2 \mathrm{BdBr}$ and $\mathrm{CN} 3 \mathrm{Bd}$ in monomer state were calculated to be $2.592 \mathrm{eV}(478 \mathrm{~nm}), 2.587 \mathrm{eV}(479 \mathrm{~nm})$ and $2.646 \mathrm{eV}(469 \mathrm{~nm})$ (Figure 6a), agreeing well with the fluorescence bands of $450 \mathrm{~nm}$ for $\mathrm{CNCzBdBr}, 455 \mathrm{~nm}$ for $\mathrm{CN} 2 \mathrm{BdBr}$ and $459 \mathrm{~nm}$ for $\mathrm{CN} 3 \mathrm{Bd}$. Considering spin orbital coupling (SOC) calculation and $\mathrm{T}_{\mathrm{n}}$ distribution together, dominated $\mathrm{T}_{\mathrm{n}}$ of $\mathrm{CNCzBdBr}, \mathrm{CN} 2 \mathrm{BdBr}$ and $\mathrm{CN} 3 \mathrm{Bd}$ in monomer state were calculated to be $2.512 \mathrm{eV}\left(\mathrm{T}_{2}, 494 \mathrm{~nm},<\mathrm{S}_{1}|\mathrm{Hso}| \mathrm{T}_{2}>=120.5 \mathrm{~cm}^{-1},<\mathrm{S}_{0}\left|\mathrm{Hso}_{\mathrm{T}}\right| \mathrm{T}_{2}>=366.4\right.$ $\left.\mathrm{cm}^{-1}\right), 2.512 \mathrm{eV}\left(\mathrm{T}_{3}, 494 \mathrm{~nm},<\mathrm{S}_{1}|\mathrm{Hso}| \mathrm{T}_{3}>=127.7 \mathrm{~cm}^{-1},<\mathrm{S}_{0}|\mathrm{Hso}| \mathrm{T}_{3}>=373.8 \mathrm{~cm}^{-1}\right)$ and 2.587 $\mathrm{eV}\left(\mathrm{T}_{4}, 479 \mathrm{~nm},<\mathrm{S}_{1}|\mathrm{Hso}| \mathrm{T}_{4}>=0.36 \mathrm{~cm}^{-1},<\mathrm{S}_{0}|\mathrm{Hso}| \mathrm{T}_{4}>=1.67 \mathrm{~cm}^{-1}\right.$ ) (Figure 6a), agreeing well with the experimental data $(452 \mathrm{~nm}$ for $\mathrm{CNCzBdBr}, 446 \mathrm{~nm}$ for $\mathrm{CN} 2 \mathrm{BdBr}$ and $452 \mathrm{~nm}$ for CN3Bd). Amazingly, there exists several excited states with strong oscillator strength in the range of $2.26 \mathrm{eV} \sim 1.65 \mathrm{eV}(550 \mathrm{~nm} \sim 750 \mathrm{~nm})$ for radical cations of $\mathrm{CNCzBdBr}, \mathrm{CN} 2 \mathrm{BdBr}$ and CN3Bd (Figure 6b, Figure S51-S54), verifying that the ultralong phosphorescence bands over $550 \mathrm{~nm}$ originate from Bd derivatives' radical cations. SOC calculation also showed that the intersystem crossing (ISC) efficiency of $\mathrm{CNCzBdBr}$ and $\mathrm{CN} 2 \mathrm{BdBr}$ were much higher than CN3Bd owing to heavy-atom effect so photo-activated room-temperature ultralong phosphorescence was not observed in PMMA film of CN3Bd (Table S10). TD-DFT results further confirmed that the short-wavelength phosphorescence band (at $\sim 450 \mathrm{~nm}$ ) was assigned to molecular phosphorescence of $\mathrm{Bd}$ derivative and the long-wavelength ultralong phosphorescence bands (over $550 \mathrm{~nm}$ ) were ascribed to Bd derivative's radical cations. 

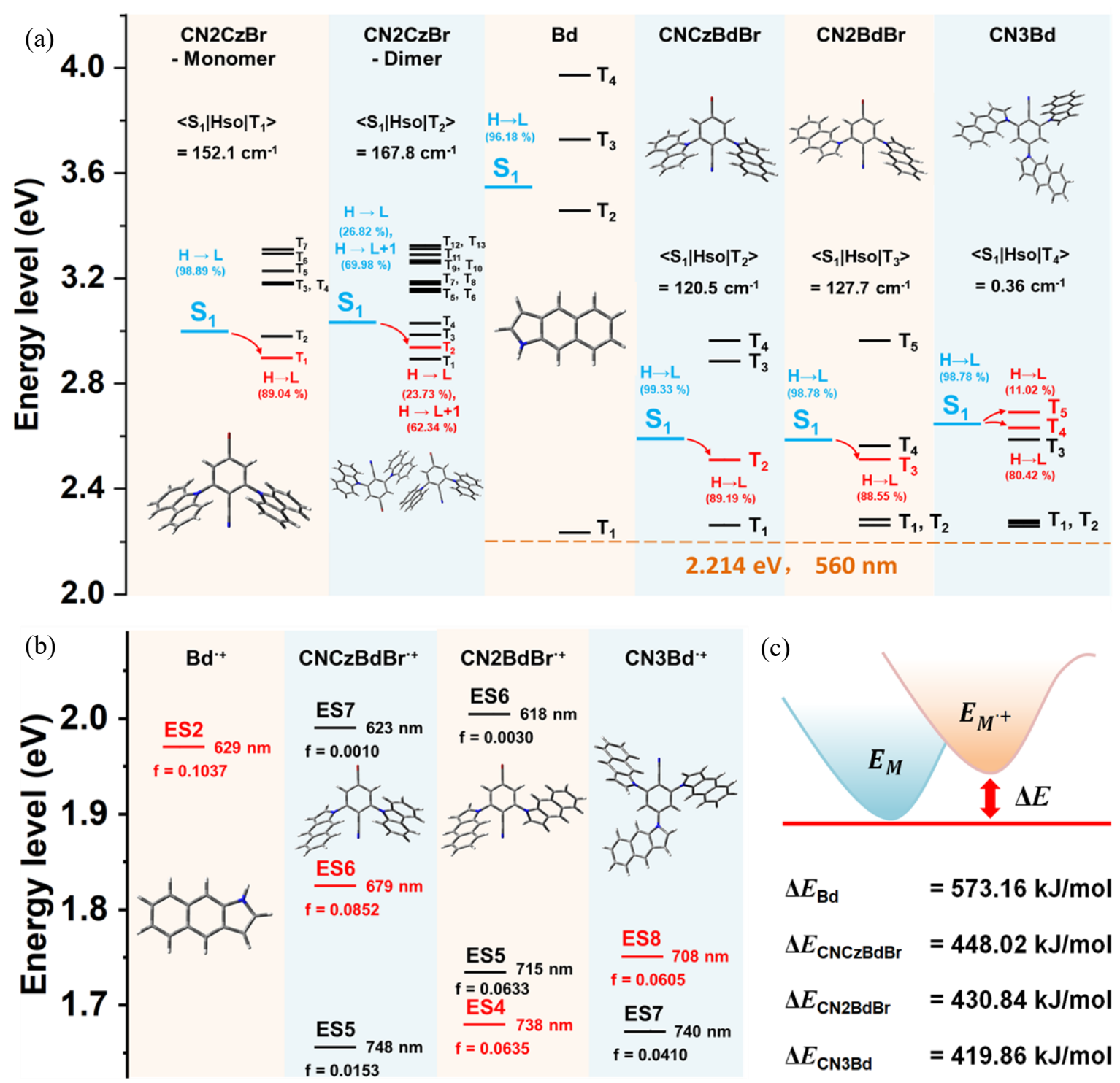

Figure 6. (a) The energy level diagrams for monomer and dimer of $\mathrm{CN} 2 \mathrm{CzBr}, \mathrm{Bd}$, $\mathrm{CNCzBdBr}, \mathrm{CN} 2 \mathrm{BdBr}$ and $\mathrm{CN} 3 \mathrm{Bd}$; (b) the energy level diagrams for $\mathrm{Bd}^{++}, \mathrm{CNCzBdBr}^{+}$, $\mathrm{CN} 2 \mathrm{BdBr}^{+}$and $\mathrm{CN} 3 \mathrm{Bd}^{++}$; (c) the energy gap between neutral molecule and corresponding racial cation for $\mathrm{Bd}, \mathrm{CNCzBdBr}, \mathrm{CN} 2 \mathrm{BdBr}$ and $\mathrm{CN} 3 \mathrm{Bd}$.

On the basis of the theoretical and experimental data, the phosphorescence mechanism of Bd derivatives were proposed as shown in Figure $1 \mathrm{c} \& 1 \mathrm{~d}$. Three necessary conditions should be satisfied to activate room temperature ultralong phosphorescence of Bd derivatives. Firstly, $\mathrm{Bd}$ derivatives should be dispersed into matrixes to prevent their 
self-aggregation which will quench phosphorescence. Secondly, the generation of $\mathrm{Bd}$ derivatives' radical cations is indispensable and photo-irradiation facilitates their generation. Thirdly, the Bd derivatives' radical cations should be stabilized by matrixes and matrixes greatly affect lifetime and PLQY of the ultralong phosphorescence.

\section{Application demonstration of photo-activated ultralong phosphorescence.}
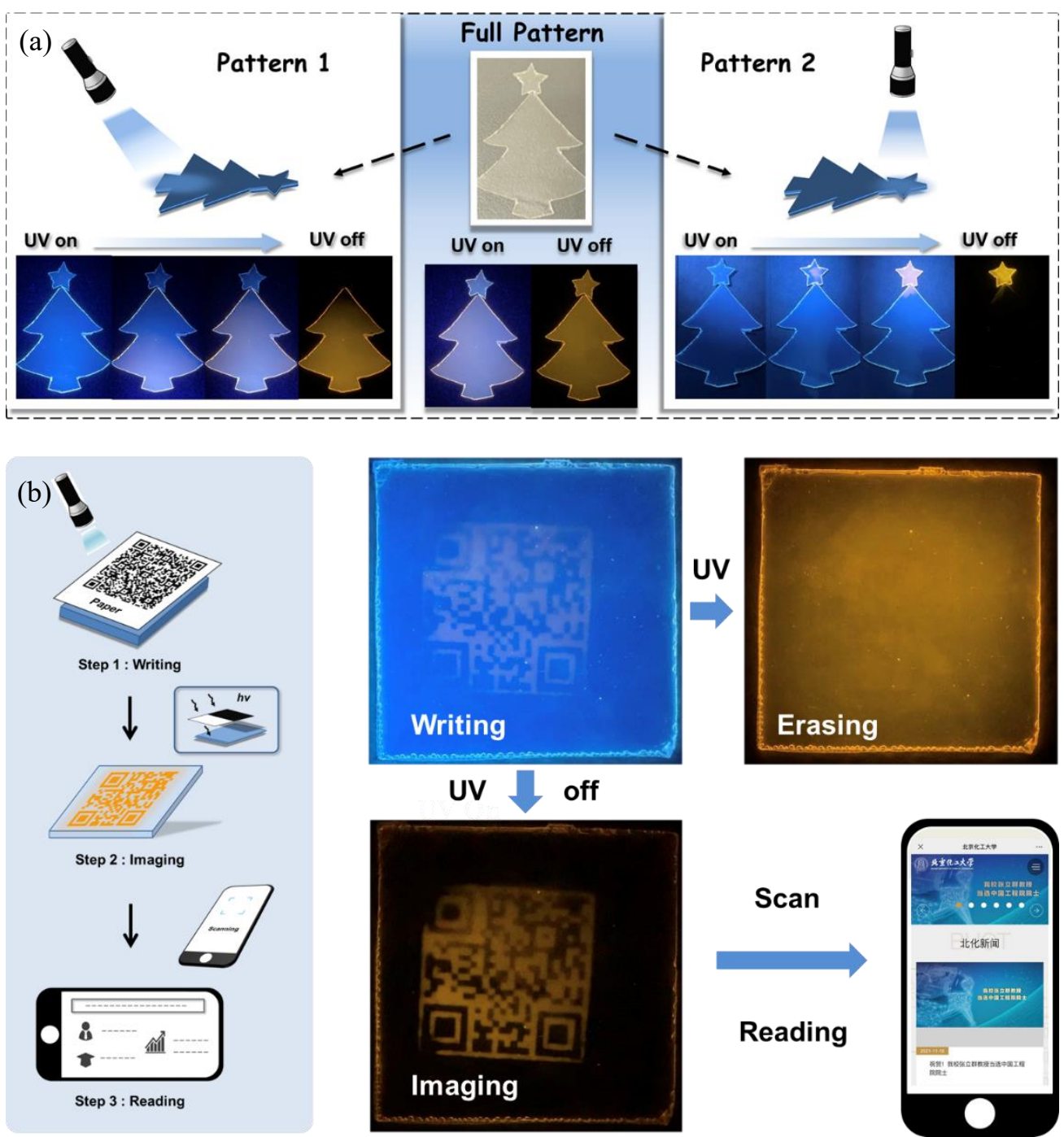

Figure 7. Applications of photo-activated ultralong phosphorescence (PMMA films doped with $\mathrm{CNCzBdBr}$ ).

Applications of photo-activated ultralong phosphorescence in doped PMMA film were 
demonstrated. The doped PMMA films can be prepared on a large scale facilely. Firstly, the doped PMMA film can be tailored into various shapes. As shown in Figure 7a, a Christmas tree was cut out. When different part of the tree was irradiated by $365 \mathrm{~nm}$ UV light, the selected part would be lighted up with yellow afterglow. Amazingly, the doped PMMA films exhibited high sensitivity to irradiation intensity. For example, a QR code was printed on a A4 white paper in black and white; then a doped PMMA film was covered by the A4 paper; when UV light irradiated the pattern above the A4 paper, the pattern would be printed on the PMMA film and further give out yellow afterglow (Figure 7b). The photo-printed yellow pattern displayed high resolution and the QR code could be successfully scanned by cellphones. Also, the QR code could be erased by further irradiation and the PMMA film could recover to initial state in less than 5 minutes at ambient condition.

\section{Conclusion}

In summary, we successfully acquired four $\mathrm{Cz} / \mathrm{Bd}$ derivatives $(\mathrm{CN} 2 \mathrm{CzBr}, \mathrm{CNCzBdBr}$, $\mathrm{CN} 2 \mathrm{BdBr}$ and $\mathrm{CN} 3 \mathrm{Bd}$ ) by using lab-synthesized $\mathrm{Cz}$ and lab-synthesized $\mathrm{Bd}$. $\mathrm{Bd}$ and its derivatives feature double groups of intrinsic phosphorescence bands, of which the short-wavelength phosphorescence band is assigned to the molecular phosphorescence of $\mathrm{Bd}$ derivative and of which the ultralong phosphorescence at long wavelengths are ascribed to $\mathrm{Bd}$ derivative's radical cations. Fascinatingly, $\mathrm{CNCzBdBr}$ and $\mathrm{CN} 2 \mathrm{BdBr}$ manifest photo-activated intrinsic ultralong phosphorescence at room temperature in PMMA film but this doesn't happen to $\mathrm{Bd}$ and $\mathrm{CN} 3 \mathrm{Bd}$. Activation of room temperature ultralong phosphorescence from $\mathrm{Bd}$ derivatives involves three factors: well dispersion with limited 
amount in matrix, generation of $\mathrm{Bd}$ derivatives' radical cations and stabilizing radical cations mediated by matrix. Generally, the intrinsic ultralong phosphorescence of $\mathrm{Bd}$ derivatives can be activated by $\mathrm{Cz}$ derivatives. However, the activation function of $\mathrm{Cz}$ derivatives can be replaced by other methods such as photo-activation or other matrixes. Importantly, the photo-activated ultralong phosphorescence is closely related to molecular structure of $\mathrm{Bd}$ derivatives and stability of Bd derivatives' radical cations so screening novel structures to optimize ultralong phosphorescence property is of great significance. Moreover, for some $\mathrm{Cz}$ systems synthesized from commercial $\mathrm{Cz}$, their ultralong phosphorescence might originate from synergistic effect of two or even more Bd derivatives. This work might be a milestone in ultralong organic phosphorescence and open a new era for its development.

\section{Methods}

Synthesis of Bd. The synthetic detail of ISO 1-5 is shown in Supporting Information. ISO-6 (0.8361 g, $5 \mathrm{mmol})$ was dissolved in pyridine $(10 \mathrm{~mL})$ in a Schlenk bottle. The mixed solution was refluxed at $90{ }^{\circ} \mathrm{C}$ for $1 \mathrm{~h}$ under $\mathrm{N}_{2}$ atmosphere. The crude product was purified by column chromatography using dichloromethane and petroleum ether (v/v, 1:2) as the eluent to obtain pure product as light yellow powder. Yield: 99\%.

${ }^{1} \mathrm{H}$ NMR $\left(400 \mathrm{MHz}, \mathrm{CDCl}_{3}\right) \delta(\mathrm{ppm}): 8.21(\mathrm{~s}, 1 \mathrm{H}), 7.98(\mathrm{dd}, J=32.0,8.0 \mathrm{~Hz}, 3 \mathrm{H}), 7.78(\mathrm{~s}$, 1H), $7.49-7.35(\mathrm{~m}, 3 \mathrm{H}), 6.73(\mathrm{~s}, 1 \mathrm{H})$.

${ }^{13} \mathrm{C}$ NMR (400 MHz, $\left.\mathrm{CDCl}_{3}\right) \delta(\mathrm{ppm}): 136.57,130.32,129.62,128.78,128.28,128.21$, 127.31, 123.75, 122.61, 118.09, 106.23, 102.02.

HR-ESI-MS Calcd. For $\mathrm{C}_{12} \mathrm{H}_{10} \mathrm{~N}[\mathrm{M}+\mathrm{H}]^{+}:$168.0813. Found: 168.0815 .

CN2CzBr: A mixture of Carbazole (1.8393 g, $11 \mathrm{mmol})$, 4-bromo-2,6-difluorobenzonltrlle 
(1.0900 g, $5 \mathrm{mmol})$ and t-BuOK (1.3465 g, $12 \mathrm{mmol})$ were dissolved in DMF (10 mL) in a Schlenk bottle and was stirred under $\mathrm{N}_{2}$ atmosphere for $24 \mathrm{~h}$ at $110{ }^{\circ} \mathrm{C}$. After the reaction was over, the resultant mixture was cooled down to room temperature and the solvent was removed under reduced pressure. The crude product was purified by column chromatography using dichloromethane and petroleum ether $(\mathrm{v} / \mathrm{v}, 1: 5)$ as the eluent to obtain pure product as white powder. Yield: $68 \%$.

${ }^{1} \mathrm{H}$ NMR $\left(400 \mathrm{MHz}, \mathrm{CDCl}_{3}\right) \delta(\mathrm{ppm}): 8.18-8.13(\mathrm{~m}, 4 \mathrm{H}), 7.93(\mathrm{~s}, 2 \mathrm{H}), 7.52(\mathrm{td}, J=7.5,1.1$ $\mathrm{Hz}, 4 \mathrm{H}), 7.38(\mathrm{dd}, J=8.1,6.1 \mathrm{~Hz}, 8 \mathrm{H})$.

${ }^{13} \mathrm{C}$ NMR $\left(101 \mathrm{MHz}, \mathrm{CDCl}_{3}\right) \delta(\mathrm{ppm}): 143.62,140.34,131.92,129.07,126.60,124.32$, $121.55,120.84,112.77,111.81,109.69$.

HR-ESI-MS Calcd. For $\mathrm{C}_{31} \mathrm{H}_{19} \mathrm{~N}_{3} \mathrm{Br}[\mathrm{M}+\mathrm{H}]^{+}:$512.0762. Found: 512.0763 .

CN2BdBr: A mixture of 4-bromo-2,6-difluorobenzonltrlle $(0.2398 \mathrm{~g}, 1.1 \mathrm{mmol})$, 1H-benzo[f]indole $(0.3679 \mathrm{~g}, 2.2 \mathrm{mmol})$ and t-BuOK $(0.3366 \mathrm{~g}, 3 \mathrm{mmol})$ were dissolved in DMF (10 mL) in a Schlenk bottle and was stirred under $\mathrm{N}_{2}$ atmosphere for $24 \mathrm{~h}$ at room temperature. After the reaction was over, the solvent was removed under reduced pressure. The crude product was purified by column chromatography using dichloromethane and petroleum ether $(\mathrm{v} / \mathrm{v}, 1: 5)$ as the eluent to obtain pure product as yellow powder. Yield: $36 \%$. ${ }^{1} \mathrm{H}$ NMR (400 MHz, $\left.\mathrm{CDCl}_{3}\right) \delta(\mathrm{ppm}): 8.23(\mathrm{~s}, 2 \mathrm{H}), 8.12(\mathrm{~s}, 1 \mathrm{H}), 8.00(\mathrm{dd}, J=18.0,6.5 \mathrm{~Hz}$, $7 \mathrm{H}), 7.70(\mathrm{~d}, J=3.6 \mathrm{~Hz}, 2 \mathrm{H}), 7.53-7.42(\mathrm{~m}, 4 \mathrm{H}), 6.99(\mathrm{dd}, J=11.7,6.0 \mathrm{~Hz}, 2 \mathrm{H})$. 
${ }^{13} \mathrm{C}$ NMR $\left(101 \mathrm{MHz}, \mathrm{CDCl}_{3}\right) \delta(\mathrm{ppm}): 145.21,136.36,131.37,130.77,130.41,129.75$, $128.88,128.26,127.91,127.64,124.83,123.88,119.56,106.17,106.02$.

HR-ESI-MS Calcd. For $\mathrm{C}_{31} \mathrm{H}_{19} \mathrm{~N}_{3} \mathrm{Br}[\mathrm{M}+\mathrm{H}]^{+}:$512.0762. Found: 512.0763.

CN3Bd: A mixture of $\mathbf{1 H}$-benzo[f]indole $(0.0501 \quad \mathrm{~g}, \quad 0.3 \mathrm{mmol})$, 4-bromo-2,6-difluorobenzonltrlle $(0.0218 \mathrm{~g}, 0.1 \mathrm{mmol})$ and t-BuOK $(0.0449 \mathrm{~g}, 0.4 \mathrm{mmol})$ were dissolved in DMF (2 mL) in a Schlenk tube and was stirred under $\mathrm{N}_{2}$ atmosphere for 24 $\mathrm{h}$ at $110^{\circ} \mathrm{C}$. After the reaction was over, the resultant mixture was cooled down to room temperature and the solvent was removed under reduced pressure. The crude product was purified by column chromatography using dichloromethane and petroleum ether (v/v, 1:3) as the eluent to obtain pure product as yellow powder. Yield: $52 \%$.

${ }^{1} \mathrm{H} \mathrm{NMR}\left(400 \mathrm{MHz}, \mathrm{CDCl}_{3}\right) \delta(\mathrm{ppm}): 8.34$ (s, 1H), 8.27 (s, 2H), 8.21 (s, 1H), $8.17(\mathrm{~s}, 2 \mathrm{H})$, $8.09(\mathrm{~s}, 2 \mathrm{H}), 8.07-7.92(\mathrm{~m}, 6 \mathrm{H}), 7.83(\mathrm{~d}, J=3.6 \mathrm{~Hz}, 2 \mathrm{H}), 7.66(\mathrm{~d}, J=3.6 \mathrm{~Hz}, 1 \mathrm{H}), 7.56-$ $7.41(\mathrm{~m}, 6 \mathrm{H}), 7.03(\mathrm{~d}, J=3.6 \mathrm{~Hz}, 2 \mathrm{H}), 6.98(\mathrm{~d}, J=3.5 \mathrm{~Hz}, 1 \mathrm{H})$.

${ }^{13} \mathrm{C}$ NMR $\left(101 \mathrm{MHz}, \mathrm{CDCl}_{3}\right) \delta(\mathrm{ppm}): 145.71,136.69,135.23,131.90,130.75,130.50$, $129.63,128.18,128.03,127.76,127.53,124.91,124.71,124.05,123.72,119.57,119.28$, $118.68,106.81,106.66,106.21,105.24$.

HR-ESI-MS Calcd. For $\mathrm{C}_{43} \mathrm{H}_{27} \mathrm{~N}_{4}[\mathrm{M}+\mathrm{H}]^{+}$: 599.2236. Found: 599.2247.

Synthesis of CNCzBdBr. A mixture of CNCzBrF (0.2950 g, $0.8 \mathrm{mmol})$, 1H-benzo[f]indole $(0.1350 \mathrm{~g}, 0.8 \mathrm{mmol})$ and $\mathrm{K}_{2} \mathrm{CO}_{3}(0.1670 \mathrm{~g}, 1.2 \mathrm{mmol})$ were dissolved in DMF $(10 \mathrm{~mL})$ in a Schlenk bottle and was stirred under $\mathrm{N}_{2}$ atmosphere for $24 \mathrm{~h}$ at room temperature. After the 
reaction was over, the solvent was removed under reduced pressure. The crude product was purified by column chromatography using dichloromethane and petroleum ether (v/v, 1:5) as the eluent to obtain pure product as yellow powder. Yield: $85 \%$.

${ }^{1} \mathrm{H}$ NMR $\left(400 \mathrm{MHz}, \mathrm{CDCl}_{3}\right) \delta(\mathrm{ppm}): 8.23(\mathrm{~s}, 1 \mathrm{H}), 8.19(\mathrm{~d}, J=8.1 \mathrm{~Hz}, 2 \mathrm{H}), 8.11(\mathrm{~d}, J=1.6$ Hz, 1H), $8.00(\mathrm{dd}, J=13.2,8.8 \mathrm{~Hz}, 3 \mathrm{H}), 7.83(\mathrm{~d}, J=1.6 \mathrm{~Hz}, 1 \mathrm{H}), 7.73(\mathrm{~d}, J=3.6 \mathrm{~Hz}, 1 \mathrm{H})$, $7.56-7.44(\mathrm{~m}, 4 \mathrm{H}), 7.43-7.36(\mathrm{~m}, 4 \mathrm{H}), 6.97(\mathrm{~d}, J=3.6 \mathrm{~Hz}, 1 \mathrm{H})$.

${ }^{13} \mathrm{C}$ NMR (101 MHz, $\left.\mathrm{CDCl}_{3}\right) \delta(\mathrm{ppm}): 145.07,143.78,140.31,136.27,131.36,130.78$, $130.45,130.29,129.79,129.06,128.27,127.66,126.54,124.88,124.29,123.93,121.51$, $120.82,119.62,113.51,109.81,108.20,106.16$.

HR-ESI-MS Calcd. For $\mathrm{C}_{31} \mathrm{H}_{19} \mathrm{~N}_{3} \mathrm{Br}[\mathrm{M}+\mathrm{H}]^{+}$: 512.0762. Found: 512.0759.

Data availability. All data that support the findings of this study are available in the online version of this paper in the accompanying Supplementary Information (including experimental methods/procedures, synthetic routes, molecular characterization of $\mathrm{Bd} / \mathrm{CN} 2 \mathrm{CzBr} / \mathrm{CNCzBdBr} / \mathrm{CN} 2 \mathrm{BdBr} / \mathrm{CN} 3 \mathrm{Bd}$, photophysical properties in solution and in solid state, PL spectra of doped PMMA films, PL spectra of doped CN2CzBr, single crystal data, TD-DFT results).

\section{References}

1. Ye, W., et al. Confining isolated chromophores for highly efficient blue phosphorescence. Nat. Mater. 20, 1539-1544(2021).

2. An, Z., et al. Stabilizing triplet excited states for ultralong organic phosphorescence. Nat. Mater. 14, 685-690(2015). 
3. Chen, C., et al. Carbazole isomers induce ultralong organic phosphorescence. Nat. Mater. 20, 175-180(2021).

4. Liao, Q., et al. 9,9-Dimethylxanthene Derivatives with Room-Temperature Phosphorescence. Angew. Chem. Int. Ed. 59, 1-6(2020).

5. Wen, Y., et al. Achieving Highly Efficient Pure Organic Single-Molecule White-Light Emitter: The Coenhanced Fluorescence and Phosphorescence Dual Emission by Tailoring Alkoxy Substituents. Adv. Opt. Mater. 8, 1901995(2020).

6. Gu, L., et al. Color-tunable ultralong organic room temperature phosphorescence from a multicomponent copolymer. Nat. Commun. 11, 944(2020).

7. Zheng, H., Wang Y., Cao P., Wu P. Color-tunable ultralong room temperature phosphorescence from EDTA. Chem. Commun. (Camb.) 57, 3575-3578(2021).

8. Li, H., et al. Fluorine-induced aggregate-interlocking for color-tunable organic afterglow with a simultaneously improved efficiency and lifetime. Chem. Sci. 12, 3580-3586(2021).

9. Wang, J., et al. Time dependent afterglow color in a single component organic molecualr crystal. Angew Chem Int Ed. 59, 10032-10036(2020).

10. Bi, X., et al. Multi-Stimuli Responsive and Multicolor Adjustable Pure Organic Room Temperature Fluorescence-Phosphorescent Dual-Emission Materials. Adv. Funct. Mater. 31, 2101312(2021).

11. Gu, L., et al. Colour-tunable ultra-long organic phosphorescence of a single-component molecular crystal. Nat. Photonics 13, 406-411(2019).

12. Jin, J., et al. Thermally activated triplet exciton release for highly efficient tri-mode organic afterglow. Nat. Commun. 11, 842(2020). 
13. Gao, H., et al. Boosting Room Temperature Phosphorescence Performance by Alkyl Modification for Intravital Orthotopic Lung Tumor Imaging. Small 17, e2005449(2021).

14. Zhen, X., et al. Ultralong Phosphorescence of Water-Soluble Organic Nanoparticles for In Vivo Afterglow Imaging. Adv. Mater. 29, 1606665(2017).

15. $\mathrm{Xu}, \mathrm{L}$., et al. Ultralong Organic Phosphorescent Nanocrystals with Long-Lived Triplet Excited States for Afterglow Imaging and Photodynamic Therapy. ACS Appl. Mater. Interfaces 12, 18385-18394(2020).

16. Gu, L., et al. Circularly Polarized Organic Room Temperature Phosphorescence from Amorphous Copolymers. J. Am. Chem. Soc. 143, 13675-13685(2021).

17. Yang, Y. D., et al. Time-dependent solid-state molecular motion and colour tuning of host-guest systems by organic solvents. Nat. Commun. 11, 77(2020).

18. Hu, J., et al. Single White-Emitting Polymers with High Efficiency, Low Roll-Off, and Enhanced Device Stability by Using Through-Space Charge Transfer Polymer with Blue Delayed Fluorescence as Host for Yellow Phosphor. Adv. Opt. Mater. 8, 1902100(2020).

19. Wang, J., et al. A facile strategy for realizing room temperature phosphorescence and single molecule white light emission. Nat. Commun. 9, 2963(2018).

20. Yang, Z., et al. Boosting the Quantum Efficiency of Ultralong Organic Phosphorescence up to $52 \%$ via Intramolecular Halogen Bonding. Angew. Chem. Int. Ed. 59, 17451-17455(2020).

21. He, Z., et al. Achieving Persistent, Efficient, and Robust Room-Temperature Phosphorescence from Pure Organics for Versatile Applications. Adv. Mater. 31, e1807222(2019).

22. Gao, W., et al. Effect of Carbazolyl Groups on Photophysical Properties of Cyanuric 
Chloride. ACS Appl. Mater. Interfaces 11, 47162-47169(2019).

23. Gan, N., et al. Manipulating the Stacking of Triplet Chromophores in the Crystal Form for Ultralong Organic Phosphorescence. Angew. Chem. Int. Ed. Engl. 58, 14140-14145(2019).

24. Xiong, Y., et al. Designing Efficient and Ultralong Pure Organic Room-Temperature Phosphorescent Materials by Structural Isomerism. Angew. Chem. Int. Ed. Engl. 57, 7997-8001(2018).

25. Liu, Y., et al. Robust White-Light Emitting and Multi-Responsive Luminescence of a Dual-Mode Phosphorescence Molecule. Adv. Opt. Mater. 9, 2001685(2021).

26. Huang, L., et al. Crystal-State Photochromism and Dual-Mode Mechanochromism of an Organic Molecule with Fluorescence, Room-Temperature Phosphorescence, and Delayed Fluorescence. Angew. Chem. Int. Ed. 58, 16445-16450(2019).

27. Kenry, Chen C., Liu B. Enhancing the performance of pure organic room-temperature phosphorescent luminophores. Nat. Commun. 10, 2111(2019).

28. Chen, C., et al. Revisiting Carbazole: Origin, Impurity, and Properties. ACS Mater. Lett. 3, 1081-1087(2021).

29. Xie, Y., et al. How the Molecular Packing Affects the Room Temperature Phosphorescence in Pure Organic Compounds: Ingenious Molecular Design, Detailed Crystal Analysis, and Rational Theoretical Calculations. Adv. Mater. 29, 1606829(2017).

30. Cai, S., et al. Enhancing Ultralong Organic Phosphorescence by Effective $\pi$-Type Halogen Bonding. Adv. Funct. Mater. 28, 1705045(2018).

31. Gu, L., et al. Dynamic Ultralong Organic Phosphorescence by Photoactivation. Angew. Chem. Int. Ed. 57, 8425-8431(2018). 
32. Wang, X., et al. Organic phosphors with bright triplet excitons for efficient X-ray-excited luminescence. Nat. Photonics 15, 187-192(2021).

33. Yuan, J., et al. Invoking ultralong room temperature phosphorescence of purely organic compounds through H-aggregation engineering. Mater. Horiz. 6, 1259-1264(2019).

34. Feng, H. T., et al. Tuning molecular emission of organic emitters from fluorescence to phosphorescence through push-pull electronic effects. Nat. Commun. 11, 2617(2020).

35. Shi, H., et al. Highly Efficient Ultralong Organic Phosphorescence through Intramolecular-Space Heavy-Atom Effect. J. Phys. Chem. Lett. 10, 595-600(2019).

36. Liang, X., et al. Organic Room-Temperature Phosphorescence with Strong Circularly Polarized Luminescence Based on Paracyclophanes. Angew. Chem. Int. Ed. Engl. 58, 17220-17225(2019).

37. Mu, Y., et al. Sensitive and Repeatable Photoinduced Luminescent Radicals from A Simple Organic Crystal. Angew. Chem. Int. Ed. Engl. 60, 6367-6371(2021).

38. Yang, Y., et al. Tunable Photoresponsive Behaviors Based on Triphenylamine Derivatives: The Pivotal Role of pi-Conjugated Structure and Corresponding Application. Adv. Mater. 33, e2104002(2021).

39. Li, J., et al. Transient and Persistent Room-Temperature Mechanoluminescence from a White-Light-Emitting AIEgen with Tricolor Emission Switching Triggered by Light. Angew. Chem. Int. Ed. 57, 6449-6453(2018).

\section{Acknowledgements}

This work is financially supported by the National Natural Science Foundation of China (22175015, 21704002), the Beijing Natural Science Foundation (2182054), the Big Science Project from BUCT (XK180301), and the Fundamental Research Funds for the Central Universities to Z. Y. Ma.

\section{Author contributions}


C.Q., Z.M.M., X.H.F., X.Z., Z.W.L. and H.W.J. performed the experiments and prepared the Supplementary Information. Z.Y.M. conceived and directed the project. Z.Y.M. and Z.M.M. wrote the manuscript. X.R.J. and H.J. helped modified the manuscript.

Competing financial interests: The authors declare no competing financial interests. 